\title{
Water vapor measurements by Howard University Raman Lidar during the WAVES 2006 campaign
}

\author{
M. Adam \\ Howard University, Washington, DC, USA \\ B. B. Demoz \\ Howard University, Washington, DC, USA \\ D. N. Whiteman \\ NASA Goddard Space Flight Center, Greenbelt, Maryland, USA \\ D. D. Venable \\ Howard University, Washington, DC, USA \\ E. Joseph \\ Howard University, Washington, DC, USA
}

A. Gambacorta
Perot System Government Services/NOAA NESDIS, Camp Springs, Maryland,
USA

J. Wei

Perot System Government Services/NOAA NESDIS, Camp Springs, Maryland, USA

M. W. Shephard

Atmospheric and Environmental Research, Inc., Lexington, Massachusetts, USA 
L. M. Miloshevich

National Center for Atmospheric Research, Boulder, Colorado, USA

C. D. Barnet

NOAA NESDIS, Camp Springs, Maryland, USA

\author{
R. L. Herman \\ Jet Propulsion Laboratory, California Institute of Technology, Pasadena, \\ California, USA \\ J. Fitzgibbon \\ National Weather Service, Sterling, Virginia, USA \\ R. Connell \\ Howard University, Washington, DC
}

Corresponding author address: Mariana Adam, Howard University, $23556^{\text {th }}$ St NW, Washington, DC 20059.

E-mail: $\underline{\text { madam@howard.edu }}$ 


\begin{abstract}
Retrieval of water vapor mixing ratio using the Howard University Raman Lidar is presented with emphasis on three aspects: i) performance of the lidar against collocated radiosondes and Raman lidar, ii) investigation of the atmospheric state variables when poor agreement between lidar and radiosondes values occurred and iii) a comparison with satellitebased measurements. The measurements were acquired during the Water Vapor Validation Experiment Sondes/Satellites 2006 field campaign. Ensemble averaging of water vapor mixing ratio data from ten night-time comparisons with Vaisala RS92 radiosondes shows on average an agreement within $10 \%$ up to $\sim 8 \mathrm{~km}$. A similar analysis of lidar-to-lidar data of over 700 profiles revealed an agreement to within $20 \%$ over the first $7 \mathrm{~km}(10 \%$ below $4 \mathrm{~km})$. A grid analysis, defined in the temperature - relative humidity space, was developed to characterize the lidar radiosonde agreement and quantitatively localizes regions of strong and weak correlations as a function of altitude, temperature or relative humidity. Three main regions of weak correlation emerge: i) regions of low relative humidity and low temperature, ii) moderate relative humidity at low temperatures and iii) low relative humidity at moderate temperatures. Comparison of Atmospheric InfraRed Sounder and Tropospheric Emission Sounder satellites retrievals of moisture with that of Howard University Raman Lidar showed a general agreement in the trend but the formers miss a lot of the details in atmospheric structure due to their low resolution. A relative difference of about $20 \%$ is usually found between lidar and satellites measurements.
\end{abstract}




\section{Introduction}

Water vapor is an important constituent of the atmosphere. The vertical distribution of moisture is important in determining atmospheric stability. Water vapor is also the most radiatively active atmospheric trace gas in the infrared (Ramanathan 1988) and thus could produce strong forcing from feedback associated with anthropogenically driven climate change (Cess 1990). In addition, there is significant variability in the distribution of water vapor on temporal and spatial scales smaller than is currently being measured by the standard techniques (radiosondes, satellites). A better understanding of both the global climatology and the smallscale variability of water vapor is required to improve simulation of current and future climates by Global Circulation Models (Moncrieff 1997; Ingram 2002). Without significantly improved water vapor data, we will continue to be limited in our understanding of important moist processes within the atmosphere (e.g., Korolev and Mazin 2003; Peter et al. 2006; Demoz et al. 2006).

Routine measurements of atmospheric water vapor have serious limitations. Upper-air radiosondes are generally launched only twice daily. The quality of the routine global upper air radiosonde measurement of water vapor is inadequate for many purposes such as radiation modeling and climate studies (GCOS-121). In the U.S., the data provided by the standard National Weather Service (NWS) radiosonde sensors can perform poorly in cold dry regions or when the package becomes wet either in clouds or during precipitation (Wade 1994; Blackwell 1996; Miloshevich et al. 2006). While current satellite remote sensing holds promise for providing high quality global water vapor observations, it is limited by its vertical and spatial resolution. Even high quality data from recent satellites (e.g., Aqua and Aura; see http://wwwcalipso.larc.nasa.gov/about/atrain.php), do not observe the fine vertical structure of the water 
vapor. Raman lidars, although generally limited to a single location, provide a high temporal and spatially resolved water vapor mixing ratio profiles and are capable of continuous measurements over hours or days (Turner and Goldsmith 1999). This paper discusses the temporal and spatial retrievals of the water vapor mixing ratio $(W V M R)$ from the Howard University Raman Lidar (HURL) and its comparisons with satellite, radiosonde, and a Raman lidar. It focuses on three main aspects: i) the performance of the relatively new HURL system done through comparisons with collocated Vaisalla RS92 radiosondes and a National Aeronautics and Space Administration, Goddard Space Flight Center (NASA/GSFC) Raman lidar, ii) a detailed analysis of the $W V M R$ as measured by lidar and the standard NWS upper air sounding package, the Sippican Mark IIA radiosonde and iii) a comparisons between HURL and satellites (Aura and Aqua) retrievals of $W V M R$. The data used in this paper were collected during the Water Vapor Validation Experiment Sondes/Satellites (WAVES) experiment that was held at the Howard University Beltsville Research Campus between 7 July and 12 August 2006. The Howard University Research Campus is located in Beltsville, Maryland, USA (39N and $76.9 \mathrm{~W}$, around $18 \mathrm{~km} \mathrm{NE}$ of Washington, DC). The objective of WAVES 2006 was to provide i) high quality measurements of water vapor and ozone profiles for comparison with Aura satellite retrievals, ii) to assess radiosondes performance and iii) to study upper troposphere water vapor measurements by Raman lidar systems. The paper is structured as follows. In Section 2, a short description of the HURL system is provided. Section 3 describes the lidar $W V M R$ calculations. Section 4 presents the data comparison results and discussions. Concluding remarks are presented in Section 5.

\section{Howard University Raman Lidar}


The Howard University Raman Lidar system was developed to provide both daytime and nighttime measurements of lower and middle tropospheric water vapor mixing ratios and aerosol scattering profiling with high temporal and spatial resolution. HURL utilizes a Nd:YAG laser that operates at the third harmonic wavelength $(354.7 \mathrm{~nm})$. HURL is a narrow field-ofview, coaxial, three-channel, fiber optic-coupled system that uses narrow bandpass $(0.25 \mathrm{~nm})$ filters to measure backscattered radiation at $354.7 \mathrm{~nm}$ and Raman scattered radiation from $\mathrm{N}_{2}$ molecules at $386.7 \mathrm{~nm}$ and from water vapor molecules at $407.5 \mathrm{~nm}$. HURL utilizes Licel Transient Recorders (http://www.licel.com/index.html) for data acquisition that simultaneously obtain both analog and photon counting signals thereby expanding the dynamic range of the detection system. The system includes an exit/receiving window that allows operations in inclement weather. A detailed description of the system is given elsewhere (Venable et al. 2005). HURL was designed jointly by Howard University and NASA/GSFC and therefore shares some technologies with that of NASA/GSFC Scanning Raman Lidar (SRL) (Whiteman et a1. 2006a). The main products of HURL are profiles of $W V M R$ and aerosol backscatter coefficient at high temporal and spatial resolution (typically, $1 \mathrm{~min}$ and $7.5 \mathrm{~m}$ ). While HURL is not designed to operate continuously it is capable of operating for extended periods of time, if needed. As mentioned above, the high temporal and spatial resolution is necessary in the study of the atmospheric dynamics, especially in the planetary boundary layer (PBL) where the dynamics is more intense. The Raman lidar products also constitute a source of validation for the satellite water vapor mixing ratio retrieval. Here, we provide initial comparison examples with retrievals provided by Atmospheric InfraRed Sounder (AIRS) on Aqua satellite and Tropospheric Emission Sounder (TES) on Aura satellite. 


\section{HURL water vapor mixing ratio calculation}

Many of the steps that are required to convert raw lidar returns (photon counts) to a usable quantity like the water vapor mixing ratio are abundantly described in the literature and will not be repeated here. However, there are some improvements in the instrument and details specific for HURL are new and thus, are briefly summarize them below.

\section{a. Gluing of signals}

Two types of signals are received by HURL: photon counting (PC) and analog (AD). This allows for analog data usage in the strong signal (lower altitude) regions and the PC data in the weak signal (high altitude) regions. These signals from different altitude ranges, must to be reconciled and "glued" to form a single profile. Before gluing the signals: i) the raw photon counts received are converted into count rates after the PC signal is corrected for system deadtime (pulse pileup), using a non-paralyzable assumption (see Whiteman et al. 2006a for details) and ii) the $\mathrm{AD}$ signal is corrected for dark current. A linear regression of the backgroundsubtracted photon counting and analog signals resulted in a system response time of $5 \mathrm{~ns}$. This value has been verified for numerous data profiles and is consistent with the pulse width of 4-5 ns of the Hamamatsu 1924 photomultiplier tubes and the high speed (250 MHz) Licel transient recorders used in HURL (Venable et al. 2005). Ordered pairs of (AD, PC) data are selected in a region where both are considered to be performing in a reasonably linear fashion and a regression is performed. The regression determines the gain coefficient that is then used to convert the AD scale to a "virtual" photon count-rate scale (Whiteman et al. 2006a). The gluing procedure consists of two steps. First, the gluing coefficients are determined for individual profiles through regression (at least 25 points are used in regression). Second, the mean gluing 
coefficients are determined for each of the aerosol, nitrogen and water vapor profiles and used for final gluing (see Adam et al. 2007, for further details). The use of the mean gluing coefficients is beneficial in regions where individual profiles could not be reliably determined (e.g., in regions where the profiles are affected by clouds).

\section{b. Temperature sensitivity correction}

When an interference filter with full width at half maximum (FWHM) less than a few nanometers (narrow filter) is used for signal detection in lidar systems to minimize daylight background, the total differential backscatter cross-section is temperature sensitive (see Measures 1984; Sherlock et al. 1999; Whiteman 2003; Adam et al. 2007; Adam 2008 for detailed discussion). Thus, the need to define the total system efficiency as a product of the

interference filter transmission efficiency $\xi\left(\lambda_{X, i}\right)$ and $\kappa\left(\lambda_{X}\right)$ that represents all the other system efficiencies (telescope reflectivity, transmission through the conditioning optics, quantum efficiency of the detector, other filters transmission, etc (see Adam 2008 for details). The transmission efficiency of the interference filter is wavelength dependent (given by manufacturer) while $\kappa\left(\lambda_{x}\right)$ is considered wavelength independent within the range of the interference filter bandpass $\Delta \lambda_{\mathrm{X}}$ (less than $2 \mathrm{~nm}$ ). Subscript " $X$ " stands for either laser emitting wavelength (L) or Raman shifted wavelength ( $H$ for water vapor and $N$ for nitrogen) while " $i$ " denotes a wavelength within the filter bandpass associated with the Raman-shifted wavelength $\lambda_{\mathrm{X}}$. The temperature dependent lidar equation for the Raman channel can then be written as (Whiteman 2003; Adam and Venable 2007; Adam 2008):

$P\left(\lambda_{X}, r\right)=P_{0} \frac{c \tau}{2} \frac{O_{X}(r) A \kappa\left(\lambda_{X}\right) N_{X}(r) F_{X}(T) \frac{d \sigma_{t}\left(\lambda_{X}, \pi\right)}{d \Omega} \xi\left(\lambda_{X}\right)}{r^{2}} \exp \left\{-\int_{0}^{r}\left[\alpha\left(\lambda_{L}, r^{\prime}\right)+\alpha\left(\lambda_{X}, r^{\prime}\right)\right] d r^{\prime}\right\}$, 
$P\left(\lambda_{\mathrm{x}}\right)$ is the backscatter power [W], $P_{0}$ is the outgoing laser power [W], $\mathrm{c}$ is the speed of light [m $\left.\mathrm{s}^{-1}\right], \tau$ is the pulse duration [s], $O_{\mathrm{X}}(r)$ is the overlap function [dimensionless], $\mathrm{A} / r^{2}$ is the solid angle [sr] defined by the telescope area $\left.\mathrm{A}^{2} \mathrm{~m}^{2}\right]$ and the distance $r[\mathrm{~m}]$ from the lidar to backscatterer. $N_{\mathrm{X}}$ is the number of molecules of the $X$ species, $\alpha$ is the extinction coefficient at laser wavelength $\lambda_{\mathrm{L}}$ and Raman shift wavelength $\lambda_{\mathrm{X}}$ and $O_{\mathrm{X}}$ is the overlap function at wavelength $\lambda_{\mathrm{x}}$. The exponential term represents the round trip transmission from the lidar to the backscatter (molecule or particle). The total extinction coefficient $\alpha$ is the sum of molecular and aerosol components $\left[\mathrm{m}^{-1}\right]$. The molecular backscatter coefficient is the product of the total number of molecules $N_{X}$ (calculated from radiosondes pressure and temperature measurements) and the total molecular differential backscatter cross-section $d \sigma_{t}\left(\lambda_{L}, \pi\right) / d \Omega\left[\mathrm{m}^{2} \mathrm{sr}^{-1}\right]$. The later is the sum of all individual cross-sections over $\mathrm{Q}, \mathrm{S}$ and $\mathrm{O}$ branches (Raman vibrational-rotational lines). The temperature dependence factor $F_{X}(T)$ at wavelength $\lambda_{X}$ is defined in the integral form (Whiteman 2003) while in practice, the computations are done using the sum (Adam and Venable 2007; Adam 2008):

$$
F_{X}(T)=\frac{\sum_{i} \frac{d \sigma\left(\lambda_{X, i}, T, \pi\right)}{d \Omega} \xi\left(\lambda_{X, i}\right)}{\frac{d \sigma_{t}\left(\lambda_{X}, \pi\right)}{d \Omega} \xi\left(\lambda_{X}\right)}
$$

where $i$ goes over all spectral lines within interference filter bandpass. $d \sigma\left(\lambda_{X, i}, T, \pi\right) / d \Omega$ and $\xi\left(\lambda_{X, i}\right)$ are the individual backscatter cross-sections and interference filter transmission efficiency (wavelength dependent) within the filter bandpass $\Delta \lambda_{X}$. The temperature data is provided from radiosounding coincident with the lidar measurements. 
Recall that the $W V M R$ is defined as the ratio between mass of water vapor to the mass of dry air. The expression of the $W V M R$, after overlaps ratio correction is applied, simply becomes (Adam and Venable 2007; Adam 2008):

$W V M R=C \kappa\left(\lambda_{N}, \lambda_{H}\right) \frac{P\left(\lambda_{H}, r\right)}{P\left(\lambda_{N}, r\right)} \frac{F_{N}(T)^{d \sigma_{t}\left(\lambda_{N}, \pi\right)} \xi\left(\lambda_{N}\right)}{F_{H}(T)^{\frac{d \sigma_{t}\left(\lambda_{H}, \pi\right)}{d \Omega}} \xi\left(\lambda_{H}\right)} \Delta \tau\left(\lambda_{N}, \lambda_{N}, r\right)$.

where $\mathrm{C} \cong 0.485$ (Whiteman et al. 2006a) and $\Delta \tau\left(\lambda_{\mathrm{N}}, \lambda_{\mathrm{H}}, \mathrm{r}\right)$ is the differential transmission (see Adam et al. 2007 for details of computation). The system calibration factor, $\kappa\left(\lambda_{N}, \lambda_{H}\right)$, is the ratio of $\kappa\left(\lambda_{\mathrm{N}}\right)$ to $\kappa\left(\lambda_{\mathrm{H}}\right)$. The computation of $F_{X}(T)$, including the calculation of the individual and total backscatter cross-sections are described in details elsewhere (Adam 2008). Following the overlap correction (next section), the ratio for the overlaps $O_{N}(r) / O_{H}(r)$ is considered unity in Eq. (3) and thus it was omitted.

\section{c. Overlap correction}

In Eq. (3) the ratio of the nitrogen overlap function to the water vapor overlap function might not be unity in the region of incomplete overlap. In order to extract useful information from that region, a correction has to be applied. In the present study, a correction function was determined using the ratios of lidar and radiosonde (Vaisala RS92) measured WVMR profiles (Turner and Goldsmith 1999; Ferrare et al. 2004; Whiteman et al. 2006a, c). A set of profiles (fifteen in this case) over the measurement period were used to derive the correction. An analytical fit for the mean ratio was determined by considering two $3^{\text {rd }}$ order polynomial fits over two regions (altitude ranges: $45-345 \mathrm{~m}$ and $345-1600 \mathrm{~m}$ ). The ratio is considered unity above $1600 \mathrm{~m}$. A difference of up to $15 \%$ (at $\sim 350 \mathrm{~m}$ ) was found and the lidar $W V M R$ profiles 
corrected accordingly. An additional improvement in the overlap correction and water vapor mixing ratio data quality was achieved, by minimizing reflections in the laboratory of the elastic signal, which we speculate contaminated the nitrogen and water vapor channels also. This new configuration of the system, which includes a baffle which shielded the transmitted laser beam from the telescope to the exit/receiving window, eliminated the observed strong increase in the elastic channel backscatter signal and the deviation from unity of the lidar-sonde WVMR ratio above $400 \mathrm{~m}$.

\section{d. Raman lidar calibration factor}

Further, routine calibration of lidar measured water vapor mixing ratio data by tracking the calibration factor, $\kappa\left(\lambda_{\mathrm{N}}, \lambda_{\mathrm{H}}\right)$ in Eq. 3, is performed by comparison of the night time lidar integrated precipitable water $(I P W)$ measurements with IPW measured using a microwave radiometer (MWR) as is routinely done in Raman lidar calibration (see for example; Turner and

Goldsmith 1999; Turner et al. 2002; Ferrare et al. 2004; Whiteman et al. 2006a; Adam and Venable 2007). The MWR IPW is assumed to be reliable, with its uncertainty in the range $0.2 \mathrm{~mm}-0.4 \mathrm{~mm}$, depending on absolute value of $I P W$ (Cimini 2003). The absolute $I P W$ measurements observed during WAVES 2006 campaign varied between $10 \mathrm{~mm}$ and $60 \mathrm{~mm}$, with most of the values being above $20 \mathrm{~mm}$. Consequently, expected errors for the MWR $I P W$ are less than $2 \%$. The MWR to lidar $I P W$ ratio is required for the lidar calibration factor for water vapor mixing ratio. For each period analyzed, as a first step, the mean and the standard deviation (STD) of the lidar calibration factor are computed and the outliers (larger than $\mathrm{STD} /$ mean $=0.01)$ excluded. With the remaining set of calibration factors, a new mean and STD are computed. The mean calibration factor is then used for the calibration of all the profiles 
during that period. As in the case of gluing coefficients, this assures that a calibration factor is obtained even in regions where it cannot be reliably calculated due to cloud or other reasons. For the entire WAVES 2006 campaign, the mean calibration factor is $\sim 501.97 \mathrm{~g} / \mathrm{g}$ while the STD is $\sim 15.68 \mathrm{~g} / \mathrm{g}$. The corresponding relative error $(100 \mathrm{STD} / \mathrm{mean})$ is found to be $3.12 \%$. Variation of the calibration factor has been reported for a number of Raman lidar systems; for example, in the case of absolute Raman calibration, Sherlock et al. (1999) reported a 10 - $12 \%$ uncertainty. For radio sounding based calibration (using RS80 type sondes), Ferrare et al. (1995) reported a 1 $\%$ change but when an Atmospheric Instrumentation Research (AIR) radiosonde was used the calibration changed by 5\% over two years. Using a Meisei RS2-91 type of radiosonde, Sakai et al. (2007) reported an $11 \%$ change over 18 months. Whiteman et al. (2006a) report a $6 \%$ change when calibration was performed with GPS IPW. Variation of the calibration factor (3\%), when performed with respect to a MWR IPW is reported by Turner and Goldsmith (1999) who combine two intensive campaigns over 1996 and 1997. The comparisons were made over ten minute averages and finally collected into 30 min bins. Ferrare et al. (2004) compared seven airborne based lidar $I P W$ with ground based MWR and found a $3 \%$ change (a variable smoothing was applied to lidar data to constrain the random error within $2-5 \%$ ). The HURL calibration constant variations reported here fall in the low range of variation in the calibration constants reported, an indication of the stability of the system over time. Because system performances are expected to change over time (degradation of components, laser power, etc), the variation will be tracked over the HURL lifetime.

\section{Data, results and discussions}


The WAVES 2006 field campaign took place at the Howard University Research Campus in Beltsville, MD, USA from July 7 to August 10. Groups from thirteen academic and government institutions participated. The key government collaborators included groups from National Ocean and Atmospheric Administration (NOAA) / NWS and NASA/GSFC. The field campaign was intended to provide high quality measurements of water vapor and ozone for validation of Aura satellite retrievals, to assess the accuracy of upper tropospheric water vapor measurements using radiosounding and to observe mesoscale processes that influence local air quality and regional water vapor variability. The operations include intensive observations by multiple radiosonde/ozonesonde sensors and several lidar systems during overpasses of Aura and other A-Train satellites. In addition to the lidar/radiosondes operations, continuous meteorological measurements were recorded using a suite of sensors: a $31 \mathrm{~m}$ instrumented tower (for temperature, pressure, relative humidity, flux and wind); various broad-band and spectral radiometers; a 2-channel microwave radiometer; a Doppler C-band radar; various aerosol chemical parameters; a $915 \mathrm{MHz}$ wind profiler operated by the Maryland Department of Environment (MDE), a sun photometer (operated by the US Agricultural Services and a part of AERONET network), and a Suominet GPS system. More information can be found on the WAVES webpage http://www.ecotronics.com/lidar-misc/waves_06/waves06.htm.

Satellite validation is often preferred in homogeneous locations: over water or at locations where pollution is low and surface albedo has been well characterized (e.g. Tobin et al. 2006). The Beltsville facility is located in a high population area and major pollution corridor in the Eastern US. It belongs to a semi-urban region where a wide range of meteorological conditions occurs though out the year. It provides an environment very different than ARM sites. Also, great opportunities for inter-agency and university collaboration exists (e.g. HU - MDE - 
NOAA - NASA). The atmospheric measurement program at Beltsville has developed expertise in upper air ozone sounding over the past several years through participation in the INTEX Ozonesonde Network Study (IONS) (Thompson et al. 2007) and the State of Maryland Department of the Environment summer air quality monitoring campaigns.

The HURL system operated over a 14 day period between July 7 and August 12 of 2006 as part of WAVES 2006. Figure 1 shows an example of a time-series of $W V M R\left(\mathrm{~g} \mathrm{~kg}^{-1}\right)$ profile data covering around 30.5 hours: starting at 00:50 UT on 4 August 2006 and ending at 07:21 UT on 5 August 2006. Temporally, convective clouds were present at the top of the PBL (better seen in aerosol backscatter ratio; see http://meiyu.atmphys.howard.edu/ adam/HRL_WAVES.html), specifically over the first 3 hours and during daytime operation, $\sim 12: 00$ and 19:30 UT on 4 August. The data gap at 16:00 UT on 4 August is due to HURL interruption due to heavy rainfall. The temporal resolution of the data is $1 \mathrm{~min}$ while the vertical resolution is $30 \mathrm{~m}$. No smoothing was applied to the data. The data represent the passage of a cold front over the site, which cleared the PBL moisture after about 00:00 UT on 5 August 2006. Note also the highly variable $W V M R$ structure in the boundary layer revealed by the Raman lidar data. A rigorous study of this case supported with modeling is in progress and will be reported elsewhere. It is shown here i) as an illustration of the HURL capability and ii) to add temporal context to comparisons of HURL and radiosonde water vapor mixing ratio profile comparison from this case discussed below. In summary, a total of 133 HURL operational hours of data were collected, of which 84 hours were during night-time and 49 hours were during day-time. Several types of radiosonde packages, collocated Raman lidars and satellite data sets were also operated. A comparison of the HURL data with these data sets is discussed in the following section. 
a) System performance. HURL - Vaisala radiosonde (RS92) comparisons

Ten comparisons with Vaisala RS92 radiosondes were available for night-time operations. However, prior to comparing lidar - sonde data values, the RS92 relative humidity $(R H)$ measurements were corrected for known measurement errors using an algorithm similar to the time-lag and empirical bias correction described by Miloshevich et al. (2006). The RS92 data were first corrected for time-lag error (slow response of the $R H$ sensor at low temperatures) based on laboratory measurements of the sensor time-constant as a function of temperature (Miloshevich et al. 2009). Then an empirical correction for mean calibration bias was applied, which was derived as a function of $R H$ and altitude from dual RS92/CFH (Cryogenic Frost point Hygrometer) soundings conducted during several experiments (including WAVES). These corrections resulted in a mean accuracy of about $\pm(4 \%+0.5 \% / \mathrm{RH})$ for all $R H$ conditions throughout the troposphere and a standard deviation of RS92-CFH differences of about 5\% (Miloshevich et al. 2009). The RS92 calibration bias below the $700 \mathrm{mb}$ level was derived in part from comparisons of RS92 to collocated MWR retrievals of IPW using the latest MWR physical retrieval algorithm (Turner et al. 2007). Daytime RS92 measurements are also affected by a solar radiation error, which is often a dry bias caused by solar heating of the $R H$ sensor (Vömel et al. 2007). A daytime RS92 correction for RH and height dependence of solar radiation error is derived from dual RS92-CFH dual soundings and dependencies of the error on the solar altitude angle is derived from the day-night difference between the RS92 and MWR measurements, with results similar to those of Cady-Pereira et al. (2008).

In forming the HURL-RS data pairs for comparison, the lidar profiles are selected according to the radio sonde trajectory (a process referred to as RS tracking) and are shown by black lines on Fig. 1 (note: dashed line indicate time of Aqua satellite overpass). The assumption 
in forming the RS tracking is that at each moment (time stamp) the atmosphere is horizontally homogeneous to account for possible horizontal shifts in the RS trajectory. A version of this technique was described by Whiteman et al. (2006c) and used during the AIRS Water Vapor Experiment (AWEX) campaign, where the authors applied a variable smoothing to the lidar data. In this case, a moving average was performed over 5 temporal profiles. An additional moving average over 31 minutes was applied for altitudes higher than $5 \mathrm{~km}$. A variable vertical smoothing was performed as follows: for altitude ranges of 1-2 km, 2-4 km, 4-6 km, 6-8 km, 8 km-up a moving average over 3, 5, 7, 9 and 11 bins, respectively, was performed (each bin represents $30 \mathrm{~m}$ ). In cases of temporally homogenous data sets, the RS tracking method gives similar results to the non-tracking averages (averaging time starts at RS launch time). In cases where there is significant atmospheric temporal variability over the course of the RS flight, large difference is found between the two methods. Consequently, the RS tracking method is used for the lidar comparison with RS. Our current methodology to track RS is based on two steps. First, mean values of the RS data are calculated for each layer corresponding to a lidar altitude bin (30 m). Next, the lidar data are linearly interpolated to match the RS time stamps corresponding to the RS means calculated in the first step. Two profile comparisons using data from Fig. 1 (the fourth and the last RS trajectories with launch times at 23:13 UT on 4 August and 06:01 UT on 5 August), are discussed to demonstrate HURL-RS92 comparisons (Figs. 2-3). The water vapor mixing ratio from two sensors on the meteorological tower (MT), at 1.5 and $31.8 \mathrm{~m}$, are also shown as asterisks in the figures.

In the first example, the lidar retrieval in Fig. 2 is limited to about $3 \mathrm{~km}$ because of low signal to noise ratio $(S N R)$ above this altitude due to daytime solar noise. In the first $2 \mathrm{~km}$, an agreement within $5 \%$ is found degrading at higher altitudes mainly due to low lidar $S N R$ (see 
also larger error bars in this region). The solid black curve and the error bars represent the mean relative difference and STD over $500 \mathrm{~m}$ blocks while the dotted curve represents the mean relative difference at $30 \mathrm{~m}$ resolution [Fig. 2(b)]. The maximum drift reached by the radiosonde $(4.8 \mathrm{~km})$ occurred at an altitude of $3.25 \mathrm{~km}$, the highest altitude considered for comparison in Fig. 2 (c). In the second example (Fig. 3), on average, the sonde profile is $10 \%$ moister than the lidar profile. Larger differences are found in the region between 2 and $5 \mathrm{~km}$ as well as above 10 $\mathrm{km}$, when the sonde drifted farther away $(\sim 13 \mathrm{~km})$. Note that between 2 and $5 \mathrm{~km}, R H$ is $\leq 3 \%$ which translates into a RS uncertainty of $21 \%$.

The profile comparisons shown above demonstrate the range of variability that can occur when comparing lidar-sonde profiles, even within this relatively short time difference. This variability in lidar-sonde differences can be due to a combination of factors: sensor performance and/or atmospheric variability. One way of minimizing these effects of variability is to perform an "ensemble average" of a large number of profiles. In Fig. 4, an ensemble average over ten events is plotted. On average, a relative difference of less than $20 \%$ below $7 \mathrm{~km}$ is found increasing up to $40 \%$ above this altitude. Moreover, the ensemble averaging revealed a moist bias for RS92 (or a dry bias for HURL) of about $4 \%$ over the first $2 \mathrm{~km}$. Note that, in Fig. 4, the spatial resolution is $30 \mathrm{~m}$ (no vertical smoothing applied). The error bars represent STD over the number of profiles averaged, shown in Fig. 4(b). In order to compare these results with other reported performances of Raman lidars, a different averaging was employed. First, relative differences are presented as averages over blocks of hundreds of meters (Whiteman et al. 2006b, 2006c; Ferrare et al. 2004; Behrendt et al. 2007). In addition, different procedures are followed when computing the error bar of the mean profile, which is not always explicitly mentioned in the published literature. Here we show two methods to calculate STD of the mean profile. In the 
first method, the mean of the relative difference is computed for each profile and for each block and then the mean relative differences computed (similar to Whiteman et al. 2006b). In the second method, for each block, STD is computed taking into consideration all the measurement points available (the population) from all available profiles (similar to Ferrare et al. 2004). Figure 4(c) shows the relative difference and the STD determined by the two methods using $500 \mathrm{~m}$ blocks in altitude. We can infer that the thick error bars (method I), can be associated with the atmospheric vertical variation while the thin error bars (method II) can be associated with both vertical and temporal atmospheric heterogeneity. The mean HURL-RS92 water vapor mixing ratio relative difference is less than $10 \%$ over the entire region, except the uppermost block. This represents a very good result as compared with similar comparisons reported.

\section{b) System performance: HURL -SRL intercomparisons}

HURL and the NASA/GSFC SRL (Whiteman et al. 2006a) were operated side by side. This setup provided an opportune time for HURL-SRL comparison because of the proximity of the lidars and because of the similar technical characteristics of the lidars. The SRL operates using the third harmonic Nd:YAG laser, and acquires data at $354.7 \mathrm{~nm}, 386.7 \mathrm{~nm}$ and $407.5 \mathrm{~nm}$. It has a frequency of $30 \mathrm{~Hz}$ and uses $\mathrm{PC}$ and $\mathrm{AD}$ acquisition. In addition to the water vapor mixing ratio and aerosol backscatter, it also measures depolarization and liquid water content using two telescopes: a $25 \mathrm{~cm}$ (high channel) and $76 \mathrm{~cm}$ (low channel). The SRL is a well-established instrument with a long history of making successful measurements of tropospheric water vapor (see Whiteman et al. 2006a-c and references within). The SRL water vapor mixing ratio for the high channel was calibrated using the same MWR used for HURL. For the period analyzed (3 August 2006), there are almost 13 hours (766 profiles) of coincidental measurements. Figure 
5(a)-(b) shows an example of individual profile comparison. A temporal and vertical smoothing was applied for both lidar data as follows. First, a temporal moving average over $11 \mathrm{~min}$ is applied at all altitudes. Next, an additional temporal moving average over 11 profiles is applied for altitudes above $5 \mathrm{~km}$. Finally, the same vertical smoothing as in the case of HURL-RS92 case is applied. The thick curve and error bars [Fig. 5(b)] represent the mean and STD over $500 \mathrm{~m}$ blocks. On average, a $10 \%$ agreement was found between the lidars, except in the altitude range between 5.5 and $6 \mathrm{~km}$. Note that the SRL has a better $S N R$ at high altitudes because it operates using a more powerful laser. Ensemble average is also performed over a maximum of 766 profiles (in the lower troposphere) with no vertical smoothing applied [Fig. 5(c)]. The error bars corresponding to the relative differences are computed using the two methods described above. Several additional criteria were followed in computing the mean profiles and their relative difference. First, the lidar profiles are restricted to a region where the noise did not overwhelm the signal, choosing only the region where the $W V M R$ is always positive. Second, only points with relative error (100 STD/mean) smaller than $30 \%$ are taken into consideration. Consequently, out of the maximum available number of profiles in the lower troposphere (766), only 30 profiles survived this restricted conditions at high altitudes [circles in Fig. 5(d)]. A similar decrease occurs for the number of points when the data are averaged over $500 \mathrm{~m}$ blocks [asterisks in Fig. 5(d)]. A mean relative difference of less than $10 \%$ below $4.5 \mathrm{~km}$ increasing to less than $20 \%$ over all altitude ranges is found. In addition, HURL WVMR profiles were moister (biased) above $2 \mathrm{~km}$ which at present is not explained. Further investigation is required to understand this behavior.

\section{c) Grid method}


Numerous comparisons of lidars and radiosondes derived water vapor mixing ratio are reported in the literature. Most of these comparison studies are presented either as profile by profile, ensemble averages or as IPW correlations. The effects of temperature and relative humidity on instrument performance are often studied separately. To visualize the instrument error characteristics in a unified form, a grid method is developed. This method is used to investigate the meteorological conditions (in terms of temperature and relative humidity) under which poor agreement occurs between the lidar and radiosonde profiles. In the present paper, the method is applied to HURL and NWS Mark IIA sondes. This study is part of a NOAA Center for Atmospheric Sciences (NCAS) and NWS long-term collaboration as part of the NWS' radiosonde testing and replacement program. The goal is to validate the new sensors using HURL and other supporting observations that are performed at Beltsville. Two examples, typical of the data during this campaign, are used (Figs. 6-7) to demonstrate the method. The temporal smoothing applied to HURL data is the same as done above in the case of HURL-RS92 comparisons. However, no vertical smoothing is applied, keeping a $30 \mathrm{~m}$ spatial resolution over the entire altitude range of the analysis. The first example, from 03:36 UT on 27 July 2006, is representative of the good comparisons with relative differences below $20 \%$ up to $6 \mathrm{~km}$, and much smaller below 2 km [Fig. 6(a-d)]. The second example, taken from 5 August 2006 at 03:30 UT, is a poor case of comparison where there is relatively large moist bias between HURL and the Mark IIA sonde data [Fig. 7(a-d)]. The thick curves in Figs. 6(d) and 7(d) plots represent the mean and STD of the relative difference computed for $500 \mathrm{~m}$ blocks.

As is evident from Fig. 1, the lidar revealed a dry region between 2 and $6 \mathrm{~km}$, where the mixing ratio decreases above the boundary layer. In such dry regions, the accuracy of the Mark IIA derived relative humidity shows substantial errors and was observed in several profiles. This 
limitation of the Mark-IIA may be a result of the errors in calibration, sensor hysteresis, and sensor response time (Blackmore and Taubvurtze 1999). According to Blackmore and Taubvurtze (1999), at low temperatures, the calibration (lock-in resistance) increases while the time response slows. Low temperatures and sensor hysteresis cause errors up to $10 \%$ in $R H$. At transition from high to low $R H$, the sensor hysteresis can also induce errors within $10 \%$ in $R H$ (drier $R H$ ). However, the present study reveals a much larger mixing ratio differences at the transition between high to low $R H$. These findings are consistent with those reported by Ferrare et al. (2004) and Sakai et al. (2007). Da Silveira et al. (2001) reported substantial large disagreements between Mark IIA and other sensors in their study of GPS-sonde intercomparison while Wang et al. (2003) reported time-lag errors and failure of the sonde to respond to humidity changes in the upper and middle troposphere. Miloshevich et al. (2006) report slow time response at low temperatures and a moist bias in middle troposphere of $10-30 \%$ as compared with RS80-H. These authors consider the measurements to be suspect between $-20^{\circ} \mathrm{C}$ and $-50^{\circ} \mathrm{C}$ and all temperatures when operated under dry conditions. Ensemble average plots in Fig. 8, clearly show the above findings; a large moist bias for sonde is revealed between $\sim 2.5$ and 5.5 $\mathrm{km}$.

Since the atmosphere can have several cold-dry regions as well as fast $\mathrm{RH}$ transition areas that result in large differences, a grid analysis in the dual variables, temperature - relative humidity $(T-R H)$, space was developed. This allows for quantification and easy visualization of instruments (dis)agreement, here expressed as the $W V M R$ root mean square error $(R M S)$. Note that the temperature and relative humidity are provided by the radiosondes and the focus here is on large discrepancies, (large RMS) between the two instruments. The methodology is as follows: for each increment of $\Delta T=10{ }^{\circ} \mathrm{C}$ and $\Delta R H=10 \%$ we compute $R M S$ as: 
$R M S=100 \sqrt{\frac{1}{n} \sum_{n}\left(\frac{W V M R_{H U R L}}{W V M R_{R S}}-1\right)^{2}} \quad[\%]$,

where $n$ represents the number of $W V M R$ data points within each $\Delta T$ and $\triangle R H$ space. The $R M S$ is then contoured in $T-R H$ space as shown in Figs. 9 and 10. The first case shows that the largest $R M S$ occurs for $\Delta T=[-30,-20]{ }^{\circ} \mathrm{C}$ and $\Delta R H=[10,20] \%$, i.e. in cold and dry regions. The second case shows the largest $R M S$ in the region characterized by $\Delta T=[0,10]{ }^{\circ} \mathrm{C}$ and $\Delta R H$ $=[10,20] \%$. Relative large $R M S(>0.5)$ occur also in boundary layer region (relatively warm and moist), characterized by $\Delta T=[10,20]{ }^{\circ} \mathrm{C}$ and $\Delta R H=[10,30] \%$. Note again that this mapping of $R M S$ into the $T$ - $R H$ space can be easily reversed and the T-altitude and RH-altitude pairs can be extracted. A plot of the data points for which $R M S_{\text {threshold }}=0.5$ are shown in Figs. $6-$ 7 by dots on the curves; shown as heavy lines. Thus, the box with the largest $R M S$ in Fig. 9 corresponds to the thick part of the curve shown in Fig. $6(\sim 6.5-9 \mathrm{~km})$. Similarly, for Fig. 10, the regions with RMS $>0.5$ correspond to the thick curves in Fig. $7(\sim 2.5-6.5 \mathrm{~km})$. In summary, the ensemble averaging of the RMS (Fig. 11) reveals the largest HURL-Mark IIA discrepancies over cold and dry regions, characterized by $\Delta T=[-30,-20]{ }^{\circ} \mathrm{C}$ and $\Delta R H=[10,20] \%$, where $R M S$ reaches $\sim 93 \%$. Relatively large values $(>0.5)$ also occur elsewhere where $R H<60 \%$ while $T$ varies. Note the box where $\Delta T=[10,20]{ }^{\circ} \mathrm{C}$ which suggest that the region is somewhere within the boundary layer. Note also that the differences in cold and dry regions should not be attributed to Mark IIA sonde (inadequate $R H$ sensor response at low $T$ ) alone; lidars also are affected by the low $S N R$ and low quantity of water vapor molecules. In other conditions, the difference is primarily attributed to the inadequacies in Mark IIA RS sensor response in high gradient moisture regions (as from high to low $R H$ ). More detailed analyses can and should be performed 
by choosing a higher resolution grid defined by smaller $\Delta T$ and $\Delta R H$ intervals than used here, provided that a statistically significant number of data points exist for each grid-box.

\section{c) WVMR HURL-satellites}

As mentioned above, one of the main objectives of the WAVES campaign was to provide ground-based measurements for the validation of the Aura sensors. However, since both Aura and Aqua overpass occurs only 15 minutes apart, both are studied. The $W V M R$ profiles derived from lidar are compared with those from TES on Aura and AIRS on Aqua satellites (for details and publications on AIRS and TES, please visit http://www-airs.jpl.nasa.gov/Documents and http://tes.jpl.nasa.gov/docsLinks/index.cfm, respectively). In brief, AIRS was launched to provide temperature and water vapor profiles or spectral radiances for assimilation in numerical weather prediction and to provide an improved understanding of the atmospheric branch of the hydrological cycle and climate processes (Auman et al. 2003; Fetzer 2006; and references therein). An ultimate goal of the AIRS validation effort is to achieve $W V M R$ RMS uncertainties of $10 \%$ over $2 \mathrm{~km}$ layers in troposphere (Fetzer et al. 2003; Tobin et al. 2006). For TES, the main objective is to measure the global profiles of tropospheric ozone and its precursors, among which water vapor is particularly important (Shephard et al. 2008 and references therein). The criteria used for selection of profiles in this study are such that the Aura satellite ground track lies within $50 \mathrm{~km}$ of the Beltsville site. Note also that the day-time comparisons were restricted to below $5 \mathrm{~km}$ altitude, due to low $S N R$ in the lidar signals or due to the presence of convective clouds in the boundary layer, while at night the altitude range for comparison extended on average to $10 \mathrm{~km}$.

AIRS Version 5 tropospheric moisture retrieval resolution as determined by the FWHM

of the averaging kernels ranges between $2.7 \mathrm{~km}$ near the surface and $4.3 \mathrm{~km}$ near the tropopause 
(Maddy and Barnet 2008), which is similar to TES performance (Shephard et al., 2008). In addition, AIRS moisture retrieval degrees of freedom for nominal mid-latitude cases is nearly 4.0, which is also very close to the TES moisture retrieval reported in Shephard et al., [2007]. We therefore would expect similar performance in the AIRS and TES water retrievals if we accounted for the a priori dependence of the AIRS retrievals using averaging kernels (Maddy and Barnet, 2008). For consistency with previous AIRS water vapor validation efforts (Whiteman et al. 2006c), we have chosen to compare the AIRS retrievals using traditional simple layer techniques (i.e., without the use of averaging kernels). In this study, AIRS level2 products are used where temperature and water vapor profiles are reported on a 100 vertical grid layers. The calculation of mean mixing ratio within a layer takes into account the conservation of the number of molecules within each layer (http://www.osdpd.noaa.gov/PSB/SOUNDINGS/ORA/AIRS_ barnet.pdf) and is given by the ratio of the water vapor to dry air column densities.

The TES temperature and water vapor volume mixing ratio are reported on a standard 67pressure level grid. The TES footprint, at Nadir, is $8 \times 5 \mathrm{~km}$. TES utilizes an optimal estimation retrieval approach to simultaneously minimize the difference between observed and model spectral radiances in order to estimate atmospheric profiles (Bowman et al. 2006). Provided with each TES retrieved profile is the corresponding averaging kernel, which describes the sensitivity of the retrieval. The FWHM of the rows of the averaging kernels provide the vertical resolution of the retrieval. To help provide some additional insight, the sum of the rows of the averaging kernels can be thought of as the fraction of information in the retrieval that comes from the measurement rather than the a priori. Note that the sensitivity of TES varies profile-to-profile depending on atmospheric state (concentration of the species of interest, temperature, etc), clouds, and constraints used in the retrieval. Since the goal of these comparisons is to validate the 
satellite measurements, the TES averaging kernels and a priori profile were applied to the sondes and/or lidar profiles in order to account for the a priori bias, sensitivity and vertical resolution of the TES retrievals (Shephard et al. 2008). The TES standard procedure maps the in situ measurements (radiosonde or lidar) to the TES reported grid levels, and then applies the TES averaging kernels $A_{x x}$ and the a priori profile $X_{a}$ to the mapped in situ profile $X_{\text {insitu }}^{\text {mappe }}$ :

$$
X_{\text {insitu }}^{\text {est }}=X_{a}+A_{x x}\left(X_{\text {insitu }}^{\text {mapped }}-X_{a}\right)
$$

Using this method we obtain a lidar or radiosonde profile that represents what TES would "see" for the same atmospheric state (thus yielding a profile that accounts for TES sensitivity and vertical resolution). The TES vertical resolution, computed at FWHM of the averaging kernels (Shephard et al. 2008) is $\sim 2 \mathrm{~km}$ from the surface up to close to $4 \mathrm{~km}, \sim 3 \mathrm{~km}$ between $4 \mathrm{~km}$ and close to $8 \mathrm{~km}$, and $3.5-4 \mathrm{~km}$ between $8 \mathrm{~km}$ and $11 \mathrm{~km}$.

During the WAVES 2006 campaign, 13 coincidences were found for AIRS-HURL water vapor mixing ratio comparison. Two examples of such a comparison for the night-time cases (4 August, overpass time 07:51 UT and 5 August, overpass time 06:56 UT) are shown in Fig. 12. The averaging was performed over $2 \mathrm{~km}$ layers in order to have a direct comparison with previous studies by AIRS community (e.g. Tobin et al 2006). The average over the $2 \mathrm{~km}$ layer was performed as following. Within each $2 \mathrm{~km}$ layer, the mean value was determined as the integral of all available points in the layer divided by the thickness of the layer $(2 \mathrm{~km})$. The common practice in the AIRS community of weighting the statistics by the water vapor layer amounts was not applied here, thus the relative differences between the lidar and AIRS are more comparable to the larger non-weighted results reported by Tobin et al. (2006). The Aura ground track was $48.5 \mathrm{~km}$ away from Beltsville on 4 August and $30.96 \mathrm{~km}$ on 5 August. In addition, the HURL-derived time-height evolution of mixing ratio (Fig. 1) during the overpass time shows a 
strong temporal and vertical variability over the region, including the presence of dry and moist layers above (e.g. $\sim 3 \mathrm{~km}, 5-6 \mathrm{~km}$ ). Note that in averaging the HURL data in $2 \mathrm{~km}$ layers in order to compare with the AIRS resolution removes a lot of the atmospheric variability and the small scale structures in the profile. The HURL/AIRS comparisons show relative differences below $20 \%$ for the 4 August case. For the August 5 case, large differences occur around $3 \mathrm{~km}$, most likely associated with the frontal surface variability. As can be seen in the original HURL profile (and also in Fig. 1), the lidar reveals a quick reduction in the water vapor mixing ratio results above the elevated moist layer lifted due to the cold frontal surface (above $2 \mathrm{~km}$ ). Thus, the layer averaged value in the $2-4 \mathrm{~km}$ altitude region is much smaller than the retrieved value by AIRS, which has a much wider footprint as discussed above. On average, AIRS captures the general shape of the lidar profiles, but fails to catch the finer atmospheric layers due to its inherent lower spatial resolution. Note also that the small scale structures reported by HURL during this time are also present in the RS data at 06:00 UT. Moreover, the values recorded at the meteorological tower (at $1.5 \mathrm{~m}$ and $31.8 \mathrm{~m}$ ) agree with lidar and RS data close to the ground. In the past, relative difference up to $30 \%$ between AIRS and SRL is reported by Whiteman et al. (2006c) for ensemble average and over a variable vertical resolution (1 km layers below $4 \mathrm{~km}$ and $2 \mathrm{~km}$ layers above). Ensemble averaging over all the WAVES 2006 six nighttime cases (not shown here) resulted in a large relative difference $(\sim 70 \%)$ centered at about $3 \mathrm{~km}$ and mostly due to contributions from the cases of 5 August 2006 at 06:56 UT and 12 August 2006 at 07:02 UT. Outside this mid-troposphere region, the relative errors are in general within $20 \%$. These results are similar to the relative difference of $30 \%$ between AIRS and SRL reported by Whiteman et al. (2006c) and the 20\% (non-water vapor layer weighted statistics) bias reported by Tobin et al. (2006) when comparing AIRS with radiosondes below $400 \mathrm{mb}(\sim 7.5 \mathrm{~km})$. The 
HURL/AIRS bias increases to $-10 \%$ around $200 \mathrm{mb}(\sim 12 \mathrm{~km})$ altitude region and the calculations were performed using $2 \mathrm{~km}$ block averages and 1500 pairs of data. However, a more robust set of comparisons is needed to get a statistically significant result. In the future, we plan to complete the analysis over the whole three years of the experiment. Note that the mean values in the layers reported by Tobin and Whiteman are computed slightly different from our approach and thus a direct comparison between various studies is always questionable.

The next examples show water vapor mixing ratio profile comparison from HURL and TES. A study by Shephard et al., (2008) describes the TES-radiosondes comparisons at Beltsville. As in the previous study, version V003 of the TES data was used in these comparisons. There were seven TES overpasses that occurred during HURL lidar operations in WAVES2006. After excluding the cloudy sky cases, only two cases for each day-time and nighttime overpass were available for comparison. For the day-time comparisons, the altitude range was 4 and $5 \mathrm{~km}$ respectively while for night-time, the altitude range was 8 and $10 \mathrm{~km}$ respectively. The HURL-TES night-time comparisons (07:15 UT on 11 July 2006 and 07:16 UT on 12 August 2006), are plotted in Fig. 13. TES products are converted from volume mixing ratio to mass mixing ratio. In the first example, the TES ground track was $31.1 \mathrm{~km}$ away from HURL. In addition, thin Cirrus clouds were present around $8-9 \mathrm{~km}$ at the time of the overpass (not shown here, see http://meiyu.atmphys.howard.edu/\%7Eadam/HRL_WAVES.html). In the second example, the TES ground track was $0.39 \mathrm{~km}$ away from the site. In the figure, both the lidar profile at its standard high vertical resolution (showing the fine water vapor profile structure) and the smoothed profile (to match the TES sensitivity) are shown. As in the case with the AIRS comparisons, the fine vertical structure caught by HURL is not seen in TES retrievals, which is expected due to satellite vertical resolution. In the first case, the TES retrieval shows 
smaller values ( $\sim 10 \%$ difference) in the first $2 \mathrm{~km}$ compared to HURL while above $3 \mathrm{~km}$ the values are larger by up to $20 \%$. In the second example, the relative difference is larger, reaching $40-68 \%$ over $3-7 \mathrm{~km}$ range. Note that HURL-CFH comparison (not shown here) revealed large differences above $3 \mathrm{~km}$, with a systematic bias increasing with height (lidar moister). On the other hand, HURL comparisons with RS92 shows better match, with lidar being drier. In the plots (c) -(d) we have added also comparisons of TES with CFH and RS92. As observed, for this particular case, TES shows a better agreement with RS92. Note that both radiosondes were launched at 06:01 UT. Further investigation is needed to compare and interpret the large differences between various sensors (HURL, SRL, RS92, CFH, AIRS and TES). Also note that this second case was presented by Shephard et al. (2008) through the comparison with CFH. Their results for this case show the maximum relative difference was found to be $\sim 30 \%$ over the same region (specifically around $500 \mathrm{mb}$ ). The authors also report ensemble average of TES and radiosonde data. The results show a mean relative difference of about $5 \%$ in the lower troposphere and about $20 \%$ in the upper troposphere (note these statistics were not weighted by the water vapor layer amount). The comparisons were made for 21 TES-RS coincidences within $150 \mathrm{~km}$ and within 1.5 hour of sonde launch. Work is in progress to validate TES retrievals using both ground-based and air-borne lidar systems and radiosonde data for which TES overpasses are within less than $50 \mathrm{~km}$ from the ground site and within less than 1 hour.

The entire date set over three years of WAVES experiments (2006-2008) will provide a robust and statistically significant set of HURL data available for satellites comparisons. Also, since the standard comparison methods used for the AIRS and TES are different, the differences in the performance of the AIRS and TES retrieval algorithms are beyond the scope of this paper. 


\section{Conclusions}

One of the HURL goals during the WAVES 2006 campaign was to test its performance. In the present study, HURL performance is compared to collocated Vaisala radiosonde (RS92), standard NWS Mark-IIA radiosonde packages, satellite measurements from AIRS on Aqua and TES on Aura satellites, and a more established Raman Lidar, the Scanning Raman Lidar (SRL) from NASA/GSFC. On average, a relative difference between HURL and RS92 below 10\% is obtained for altitudes up to $8 \mathrm{~km}$. The relative difference with the respect to SRL is on average less than $20 \%$ over $\sim 7 \mathrm{~km}$ and less than $10 \%$ below $4.5 \mathrm{~km}$. Within HU- NOAA collaboration, one goal was to test the new NWS sensors and validate them with respect to HURL measurements. Within these analyses, a grid method was developed to reveal regions with strong or weak agreement (quantified by $R M S$ ) and characterize them in terms of $T$ and $R H$. Ensemble average over 15 cases showed two main regions where large discrepancies occur. While one occurs at cold $T$ and low $R H$ (where usually RS $R H$ sensors do not respond properly while lidar has a poor $S N R)$ the other occurs at either milder $T(-20-+10){ }^{\circ} \mathrm{C}$ and low $R H(10-20) \%$ or low temperatures $(-30--20){ }^{\circ} \mathrm{C}$ and larger $R H(20-70) \%$. The typical situation for the later case is when a strong gradient occurs in $R H$ (usually above the PBL) where we speculate that the RS $R H$ sensor does not respond accurately at this change. Further investigations as well as laboratory tests are required to confirm our suppositions.

HURL compared relatively well with satellite retrievals from two satellite sensors (AIRS on Aqua and TES on Aura). The main water vapor mixing ratio trend is captured in the satellite data but the details of the atmospheric layers, shown by the lidar, were due to their low resolution. In the present work, discrepancies in the order of $\sim 20 \%$ are found between lidar and both AIRS and TES. As mentioned, AIRS and TES retrievals follow different approaches thus a 
comparison of performance of the AIRS and TES retrieval algorithms is beyond the scope of this paper. HURL-AIRS comparisons were made in $2 \mathrm{~km}$ atmospheric layers while TES comparisons were performed on satellite levels and from TES prospective (i.e. applying averaging kernels and a priori profiles). Although generally in agreement in the moisture trends, a $20 \%$ relative difference and in specific cases a relative difference of up to $90 \%$ was found just above the boundary layer. Further investigation into obtaining robust HURL-AIRS statistics is needed and is underway. While RS provides a high spatial resolution over a range up to 20-30 km as support for satellites validation, a Raman lidar can provide high-resolution profiles over the lower and middle troposphere $(\sim$ over $10 \mathrm{~km}$, depending on the lidar $S N R)$. The satellite and lidar observations are complementary in trying to monitor the atmospheric water vapor, as the satellites provide global spatial coverage, and the lidar provides high vertical and spatial observations at a single location. However, care has to be taken when performing comparisons between the measurements due their different resolution.

\section{Acknowledgements}

This research was partially supported by NOAA Educational Partnership Program Cooperative Agreement and NASA grants. 


\section{References}

Adam, M., D. D. Venable, R. Connell, E. Joseph, D. N. Whiteman, and B. B. Demoz, 2007: Performance of the Howard University Raman Lidar during 2006 WAVES campaign, $J$. Optoelec. Adv. Mater., 9, 3522-3528.

, and D. D. Venable, 2007: Systematic distortions in water vapor mixing ratio and aerosol scattering ratio from a Raman lidar, SPIE 6750, DOI:10.1117/12.738205.

, 2008: Notes on temperature-dependent lidar equations, in press to J. Atmos. Oceanic Technol. (http://ams.allenpress.com/perlserv/?request=get-toc-aop\&issn=1520-0426), doi: 10.1175/2008JTECHA1206.1

Aumann, H. H., M. T. Chahine, C. Gautier, M. D. Goldberg, E. Kalnay, L. M. McMilin, H. Revercomb, and P. W. Rosenkranz, 2003: AIRS/AMSU/HSB on the aqua mission: Design, science objectives, data products, and processing systems, IEEE Trans. Geosci. Remote Sens., 41, 253-264.

Behrendt, A., V. Wulfmeyer, P. Di Girolamo, C. Kiemle, H.-S. Bauer, T. Schaberl, D. Summa, D. N. Whiteman, B. B. Demoz, E. V. Browell, S. Ismail, R. Ferrare, S. Kooi, G. Ehret, and J. Wang, 2007: Intercomparison of water vapor data measured with lidar during IHOP_2002. Part I: Airborne to ground-based lidar systems and comparisons with chilled-mirror hygrometer radiosondes, J. Atmos. Oceanic Tecnol., 24, doi:10.1175/JTECH1924.1, 3-21.

Bowman, K. W., et al., 2006: Tropospheric emission spectrometer: Retrieval method and error analysis, IEEE Trans. Geosci. Remote Sens., 44, 1297-1307, doi:10.1109/TGRS.2006.871234. 
Blackmore, W., and B. Taubvurtzel, 1999: Environmental chamber tests of NWS radiosonde relative humidity sensors, paper presented at $15^{\text {th }}$ International conference on interactive information and processing systems, Am. Meteor. Soc., Dallas, TX.

Blackwell, K. G., J. P. McGuirk, 1996: Tropical upper-tropospheric dry regions from TOVS and Rawinsondes, J. Appl. Meteorol., 25, 464-481.

Cady-Pereira, K.E., M.W. Shephard, D.D. Turner, E.J. Mlawer, S.A. Clough, and T.J. Wagner, 2008: Improved daytime column-integrated precipitable water vapor from Vaisala radiosonde humidity sensors. J. Atmos. Oceanic Technol., 25, 873-883.

Cimini, D., 2003: Accuracy of ground-based microwave radiometer and balloon-borne measurements during the WVIOP2000 field experiment, IEEE Trans. Geosci. Remote Sens., 41, $2605-2615$

Cess, R. D., G. L. Potter, J.P. Blanchet, G. J. BOER, A. D. Delgenio, M. Deque, V. Dymnikov, V. Galin, W. L. Gates, S. J. Ghan, J. T. Kiehl, A. A. Lacis, H. Letreut, Z. X. Li, X. Z. Liang, B. J. Mcavaney, V. P. Meleshko, J. F. B. Mitchell, J. J. Morcrette, D. A. Randall, L. Rikus, E. Roeckner, J. F. Royer, U. Schlese, D. A. Sheinin, A. Slingo, A. P. Sokolov, K. E. Taylor, W. M. Washington, R. T. Wetherald, I. Yagai, M. H. Zhang, 1990: Intercomparison and Interpretation of Climate Feedback Processes in 19 Atmospheric General Circulation Models, J. Geophys. Res., 95 (D10), 16601-16615.

Da Silveira, R. B., G. Fisch, L.A.T. Machado, A. M. Dall'Antonia Jr, L. F. Sapucci, D. Fernandes, J. Nass, 2003: Executive summary of the WMO intercomparison of GPS radiosondes, WMO/TD No. 1153, (http://www.wmo.ch/pages/prog/www/IMOP/ publications/IOM-76-GPSSO/Intercomp-RSO-Brazil2001-ExecSummary.pdf). 
Demoz, B, C. Flamant, T. Weckwerth, D. Whiteman, K. Evans, F. Fabry, P. Di Girolamo, D. Miller, B. Geerts, W. Brown, G. Schwemmer, B. Gentry, W. Feltz, and Z. Wang, 2006: The dryline on 22 May 2002 during IHOP_2002: convective-scale measurements at the profiling site, Mon. Wea. Rev., 134, $294-310$.

Ferrare, R. A., S. H. Melfi, D. N. Whiteman, K. D. Evens, F. J. Schmidlin, and D. O'C. Starr, 1995: A comparison of water vapor measurements made by Raman lidar and radiosondes, Atmos. Oceanic Technol., 12, 1177-1195.

, E. V. Browell, S. Ismail, S. A. Kooi, L. H. Brasseur, V. G. Brackett, M. B. Clayton, J. D. W. Barrick, G. S. Diskin, J. E. M. Goldsmith, B. M. Lesht, J. R. Podolske, G. W. Sachse, F. J. Schmidlin, D. D. Turner, D. N. Whiteman, D. Tobin, L. M. Miloshevich, H. E. Revercomb, B. B. Demoz, and P. Di Girolamo, 2004: Characterization of upper-troposphere water vapor measurements during AFWEX using LASE, J. Atmos. Oceanic Technol., 21, 1790-1808.

Fetzer, E. J., L. M. McMillin, D. Tobin, H. H. Aumann, M. R. Gunson, W. W. McMillan, D. E. Hagan, M. D. Hofstadter, J. Yoe, D. N. Whiteman, J. E. Barnes, R. Bennartz, H. Vömel, V. Walden, M. Newchurch, P. J. Minnett, R. Atlas, F. Schmidlin, E. T. Olsen, M. D. Goldberg, S. Zhou, H. Ding, W. L. Smith, and H. Revercomb, 2003: AIRS/AMSU/HSB validation, IEEE Trans. Geosci. Remote Sens., 41, 418-431.

Fetzer, E. J., 2006: Preface to special section: Validation of Atmospheric Infrared Sounder obsevations, J. Geophys. Res., 111, D09S01, doi:10.1029/2005JD007020.

Goldsmith, J. E. M, F. H. Blair, S. E. Bisson, and D. D. Turner, 1998: Turn-key Raman lidar for profiling atmospheric water vapor, clouds, and aerosols, Appl. Opt., 37, 4979-4990. 
GCOS-121, 2008: Report of the GCOS Reference Upper-Air Network Implementation Meeting, Lindenberg, Germany, 26-28 February 2008. GCOS-121, WMO Tech. Doc. 1435, 49 pp. (http://www.wmo.int/pages/prog/gcos/Publications/gcos-121.pdf)

Herzberg, G., 1950: Molecular spectra and molecular structure. 1. Spectra of diatomic molecules, Second edition, Van Nostrand Reinhold Company, New York, 658 pp.

Ingram, W. J., 2002: On the robustness of the water vapor feedback: GCM vertical resolution and formulation, J. Climate, 15, 917-921.

Korolev, A. V., and I. P. Mazin, 2003: Supersaturation of water vapor in clouds, J. Atmos. Sci., 60, 2957-2974.

Maddy, E.S., and C.D. Barnet, 2008: Vertical Resolution Estimates in Version 5 of AIRS Operational Retrievals, IEEE Trans. Geosci. Remote Sens., 46, 2375-2384, doi:10.1109/TGRS.2008.917498

Miloshevich, L. M., H. Vömel, D. Whiteman, B. Lesht, F. J. Schmidlin, and F. Russo, 2006: Absolute accuracy of water vapor measurements from six operational radiosondes types launched during AWEX-G and implications for AIRS validation, J. Geophys. Res., 111, doi: 1029/2005JD006083.

, H. Vömel, D. N. Whiteman, and T. Leblanc, 2009: Accuracy assessment and correction of Vaisala RS92 radiosonde water vapor measurements, submitted to JGR

Moncrieff, M. W., S. K. Krueger, D. Gregory, J.-L. Redelsperger, and W.-K. Tao, 1997: GEWEX Cloud System Study (GCSS) Working Group 4: Precipitating convective cloud systems, Bull. Amer. Meteor. Soc., 78, 831-845. 
Peter, T., C. Marcolli, P. Spichtinger, T. Corty, M. B. Baker, and T. Koop, 2006: When the dry air is too humid, Science, 314, 1399-1402.

Ramanathan, V., 1988: The Greenhouse Theory of Climate Change: A Test by an Inadvertent Global Experiment, Science, 240, 293-299.

Sakai, T., T. Nagai, M. Nakazato, T. Matsumura, N. Orikasa and Y. Shoji, 2007: Comparisons of Raman lidar measurement of tropospheric water vapor profiles with radiosondes, hygrometers, on the meteorological observation tower, and GPS at Tsukuba, Japan, J. Atmos. Oceanic Technol., 24, 1407-1423

Shephard, M. W., R. L. Herman, B. M. Fisher, K. E. Cady-Pereira, S. A. Clough, V. H. Payne, D. N. Whiteman, J. P. Comer, H. Vömel, L. M. Milosevich, R. Forno, M. Adam, G. B. Osterman, A. Eldering, J. R. Worden, L. R. Brown, H. M. Worden, S. S. Kulawik, D. M. Rider, A. Goldman, R. Beer, K. W. Bowman, C. D. Rodgers, M. Luo, C. P. Rinsland, M. Lampel, M. R. Gunson, 2008: Comparison of Tropospheric Emission Spectrometer (TES) Water Vapor Retrievals with In Situ Measurements, J. of Geophys. Res., 113, D15S24, doi:10.1029/2007JD008822.

Sherlock, V., A. Hauchecome, and J. Lenoble, 1999: Methodology for the independent calibration of Raman backscatter water-vapor lidar systems, Appl. Opt., 36, 5816-5837.

Thompson, A. M., J. B. Stone , J. C. Witte, S. K. Miller, S. J. Oltmans, T. L. Kucsera , K. L. Ross, K. E. Pickering, J. T. Merrill, G. Forbes, D. W. Tarasick , E. Joseph , F. J. Schmidlin , W. W. McMillan , J. Warner , E. J. Hintsa, and J. E. Johnson, 2007: Intercontinental Chemical Transport Experiment Ozonesonde Network Study (IONS) 2004: 2. Tropospheric ozone budgets and variability over northeastern North America, J. Geophys. Res., 112, D12S13, doi:10.1029/2006JD007670. 
Tobin, D. C., H. E. Revercomb, R. O. Knutsen, B. M. Lesht, L. L. Strow, S. E. Hannon, W. F. Feltz, L. A. Moy, E. J. Fetzer, and T. S. Cress, 2006: Atmospheric radiation measurement site atmospheric state best estimates for Atmospheric Infrared Sounder temperature and water vapor retrieval validation, J. Geophys. Res., 111, D09S14, doi:10.1029/2005JD006103.

Turner, D. D., J. E. M. Goldsmith, 1999: Twenty-four-hour Raman lidar water vapor measurements during the Atmospheric radiation Measurement program's 1996 and 1997 water vapor intensive observation periods, J. Atmos. Oc. Technol., 16, 1062-1076.

, R. A. Ferrare, L. A. Heilman Brasseur, W. F. Feltz, T. P. Tooman, 2002: Automated retrievals of water vapor and aerosol profiles from an operational Raman lidar, J. Atmos Oceanic Technol., 19, 37-50.

, S. A. Clough, J. C. Liljegren, E. E. Clothiaux, K. E. Cady-Pereira and K. L. Gaustad, 2007: Retrieving Liquid Water Path and Precipitable Water Vapor from The Atmospheric Radiation Measurement (ARM) Microwave Radiometers, IEEE Trans. Geosci. Remote Sens., 45, $3680-3690$

Venable, D. D., E. Joseph, D. N. Whiteman, B. Demoz, R. Connell, and S. Walford, 2005: Development of the Howard University Raman Lidar, paper presented at $2^{\text {nd }}$ Symposium on Lidar Atmospheric Applications, $85^{\text {th }}$ Annual Meeting of the Am. Meteor. Soc., San Diego, CA.

Vomel, H., D. E. David, and K. Smith, 2007: Accuracy of tropospheric and stratospheric water vapor measurements by a cryogenic frost point hygrometer: instrumental details and observations, J. Geophys. Res., 112, D083305, doi:10.1029/2006JD007224.

Wade, C. G., 1994: An Evaluation of Problems Affecting the Measurement of Low Relative Humidity on the United States Radiosonde, J. Atm.Oc. Technol., 11, 687-700. 
Wang, J. H., D. J. Carlson, D. B Parsons, T. F. Hock, D. Lauritsen, H. L. Cole, C. Beyerle, and E. Chamberlain, 2003: Performance of operational radiosonde humidity sensors in direct comparison with a chilled mirror dew-point hygrometer and its climate implication, Geophys. Res. Lett., 30, doi: 10.1029/2003GL016985.

Whiteman, D.N., 2003: Examination of the traditional Raman lidar technique. I. Evaluating the temperature-dependent lidar equations, Appl. Opt., 42, 2571-2592.

, B. Demoz, P. Di Girolamo, J. Comer, I. Veselovskii, K. Evans, Z. Wang, M. Cadirola, K. Rush, G. Schwemmer, B. Gentry, S. H. Melfi, B. Mielke, D. Venable, and T. Van Hove, 2006a: Measurements during the International $\mathrm{H}_{2} \mathrm{O}$ Project. Part I: Instrumentation and Analysis Techniques, J. Atmos. Oceanic Technol., 23, 157-169.

, B. Demoz, P. Di Girolamo, J. Comer, I. Veselovskii, K. Evans, Z. Wang, D. Sabatino, G. Schwemmer, B. Gentry, R-F. Lin, A. Behrendt, V. Wulfmeyer, E. Browell, R. Ferrare, S. Ismail, J. Wang, 2006b: Measurements during the International $\mathrm{H}_{2} \mathrm{O}$ Project. Part II: Case studies, $J$. Atmos. Oc. Techn., 23, 170-183.

, F. Russo, B. Demoz, L. M. Miloshevich, I. Veselovskii, S. Hannon, Z. Wang, H. Vömel, F. Schmidlin, B. Lesht, P.J. Moore, A.S. Beebe, A. Gambacorta, and C. Barnet, 2006c: Analysis of Raman lidar and radiosonde measurements from the AWEX-G field campaign and its relation to Aqua validation, J. Geophys. Res., 111, D09S09,doi 10.1029/2005JD006429. 


\section{List of Figures}

FIG. 1. Temporal series of water vapor mixing ratio from 4 and 5 August 2006. Black curves represent the trajectory of the radiosondes launched during lidar measurements. The thin black vertical lines represents the AIRS overpasses (7:51 UT on 4 August and 6:56 on \% August).

FIG. 2. (a) Water vapor mixing ratio as measured by HURL and RS92 for 4 August 2006, 23:13 UT. MT stands for meteorological tower. (b) The relative difference between RS and HURL. The black curves and error bars represent the mean and STD over $500 \mathrm{~m}$ blocks. (c) RS trajectory.

FIG. 3. Same as FIG. 2, for 5 August 2006, 06:01 UT.

FIG. 4. Water vapor mixing ratio ensemble averaging for the night-time coincidences. (a) Relative difference with respect to RS92. The error bars represent the STD of over the number of profiles. (b) Number of profiles available for ensemble average. Altitude resolution for (a) and (b) is $30 \mathrm{~m}$. In (c), the thick error bars represent the STD over the number of profiles while the thin error bars represent the STD over all measurements (points) available in a block (See text for explanation). (d) Number of profiles (open circles) and number of points (asterisks) available for ensemble average for each $500 \mathrm{~m}$ block.

FIG. 5. (a) Water vapor mixing ratio as measured by HURL and SRL for 3 August 2006, 07:13 UT. MT stands for meteorological tower. (b) The relative difference between SRL and HURL. The thick curves and error bars represent the mean and STD over $500 \mathrm{~m}$ blocks. (c) Ensemble relative difference between HURL and SRL. The thin and thick errors bars are computed according to the two methods (see text). (d) Number of lidar profiles (open circles) and number of points (asterisks) available for each $500 \mathrm{~m}$ block. 
FIG. 6. Water vapor mixing ratio as measured by HURL and NWS Sippican Mark IIA on 27 July 2006, 3:36 UT. (a)-(b) Temperature and relative humidity during RS flight. (c) WVMR; MT stands for meteorological tower. (d) Relative difference with respect to RS. The Thick curve represents the mean profiles over $500 \mathrm{~m}$ blocks.

FIG. 7. Same as FIG.. 6, for 5 August 2006, 3:30 UT.

FIG. 8. (a) Relative difference with respect to Mark IIA. The thick error bars represent the STD over the number of profiles while the thin error bars represent the STD over all measurements (points) available in a block. See text for explanation. (b) Number of lidar profiles (open circles) and number of points (asterisks) available for each $500 \mathrm{~m}$ block.

FIG. 9. HURL - Mark IIA RS grid comparison for 27 July 2006, 3:36 UT. (a) Number of events for each grid-box, characterized by $\Delta \mathrm{T}=10{ }^{\circ} \mathrm{C}$ and $\Delta \mathrm{RH}=10 \%$. (b) $R M S$ [\%] for each gridbox. The largest $R M S$ occurs over the region characterized by $\mathrm{T}=[-30,-20]{ }^{\circ} \mathrm{C}$ and $\mathrm{RH}=[10$, $20] \%$.

FIG. 10. HURL - Mark IIA RS grid comparison for 5 August 2006, 3:30 UT. (a) Number of events for each grid-box, characterized by $\Delta \mathrm{T}=10{ }^{\circ} \mathrm{C}$ and $\Delta \mathrm{RH}=10 \%$. (b) $R M S$ [\%] for each box. The largest $R M S$ occurs over the region characterized by $\mathrm{T}=\left[0,10{ }^{\circ} \mathrm{C}\right.$ and $\mathrm{RH}=[10,20]$ $\%$.

FIG. 11. HURL - Mark IIA RS grid comparison for the ensemble averaging over all 15 comparisons. (a) Number of events for each grid-box, characterized by $\Delta \mathrm{T}=10{ }^{\circ} \mathrm{C}$ and $\Delta \mathrm{RH}=$ $10 \%$. (b) $R M S[\%]$ for each grid-box. The largest $R M S$ occurs over the region with $\mathrm{T}=[-30,-20]$ ${ }^{\circ} \mathrm{C}$ and $\mathrm{RH}=[10,20] \%(\mathrm{RMS}=95 \%)$. Relatively large $R M S$ can be observed over regions with $\mathrm{T}=[-30,-20]{ }^{\circ} \mathrm{C}$ and $\mathrm{RH}=[20,30] \%(R M S=62.4 \%)$ and other regions with $\mathrm{T}=[-30,-20]{ }^{\circ} \mathrm{C}$ and $\mathrm{RH}=[20,70] \%$ or $\mathrm{T}=[-20,20]^{\circ} \mathrm{C}$ and $\mathrm{RH}=[10,20] \%$. 
FIG. 12. (a) - (c) HURL-AIRS water vapor mixing ratio for 4 August 2006 (Aqua overpass 07:51 UT) and 5 August 2006 (Aqua overpass 06:56 UT). The HURL profiles are shown at both original resolution and averaged over $2 \mathrm{~km}$ layers. (b) - (d) Relative difference with respect to HURL within $2 \mathrm{~km}$ layers.

FIG. 13. (a) HURL-TES water vapor mixing ratio for 11 July 2006, Aura overpass 07:15 UT. (b) Relative difference with respect to HURL after applying a priori profile and kernels. (c) HURLTES-CFH-RS92 water vapor mixing ratio for 12 August 2006, Aura overpass 07:16 UT. (d) Relative difference with respect to HURL, CFH and RS92 after applying a priori profile and kernels. X stands for HURL, CFH or RS92. 


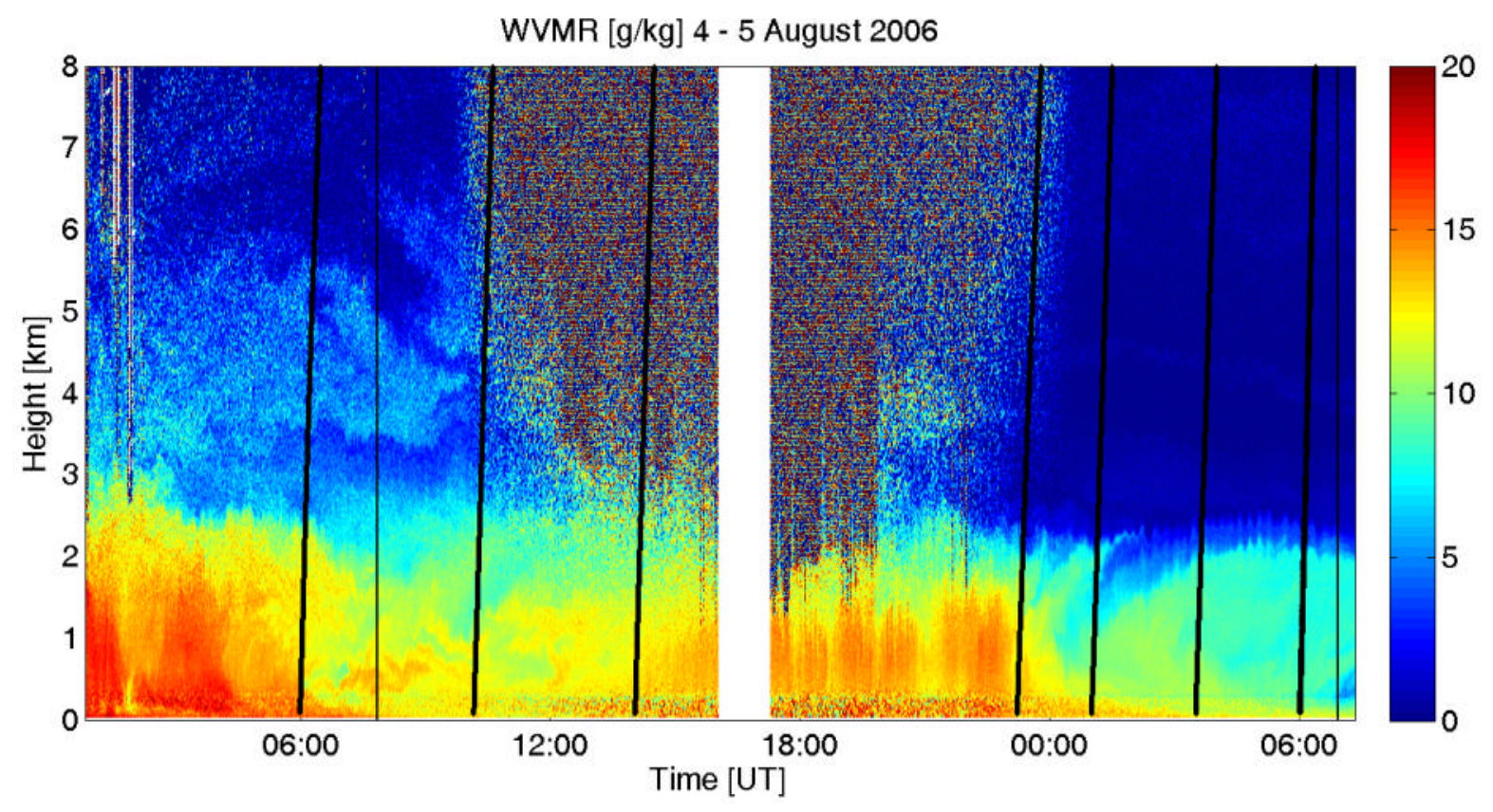

FIG. 1. Temporal series of water vapor mixing ratio from 4 and 5 August 2006. Black curves represent the trajectory of the radiosondes launched during lidar measurements. The thin black vertical lines represents the AIRS overpasses (7:51 UT on 4 August and 6:56 on \% August). 

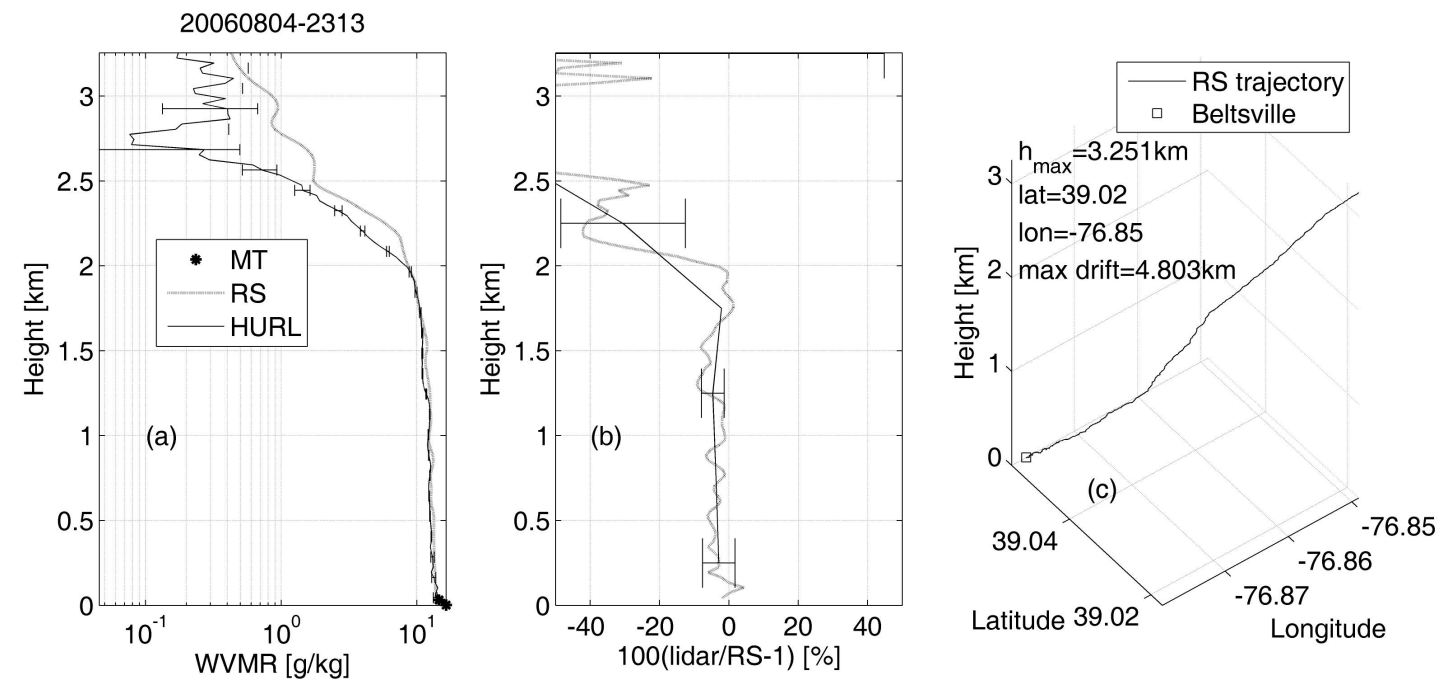

FIG. 2. (a) Water vapor mixing ratio as measured by HURL and RS92 for 4 August 2006, 23:13 UT. MT stands for meteorological tower. (b) The relative difference between RS and HURL. The black curves and error bars represent the mean and STD over $500 \mathrm{~m}$ blocks. (c) RS trajectory. 

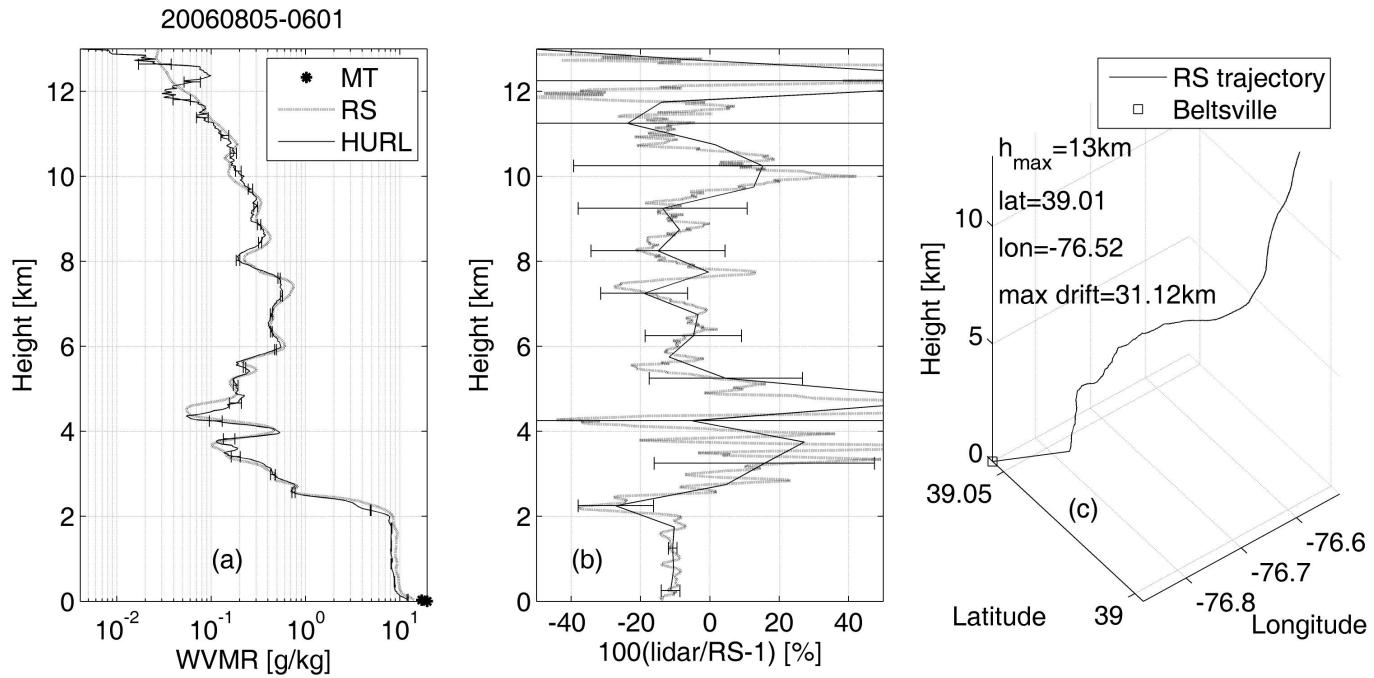

FIG. 3. Same as FIG. 2, for 5 August 2006, 06:01 UT. 

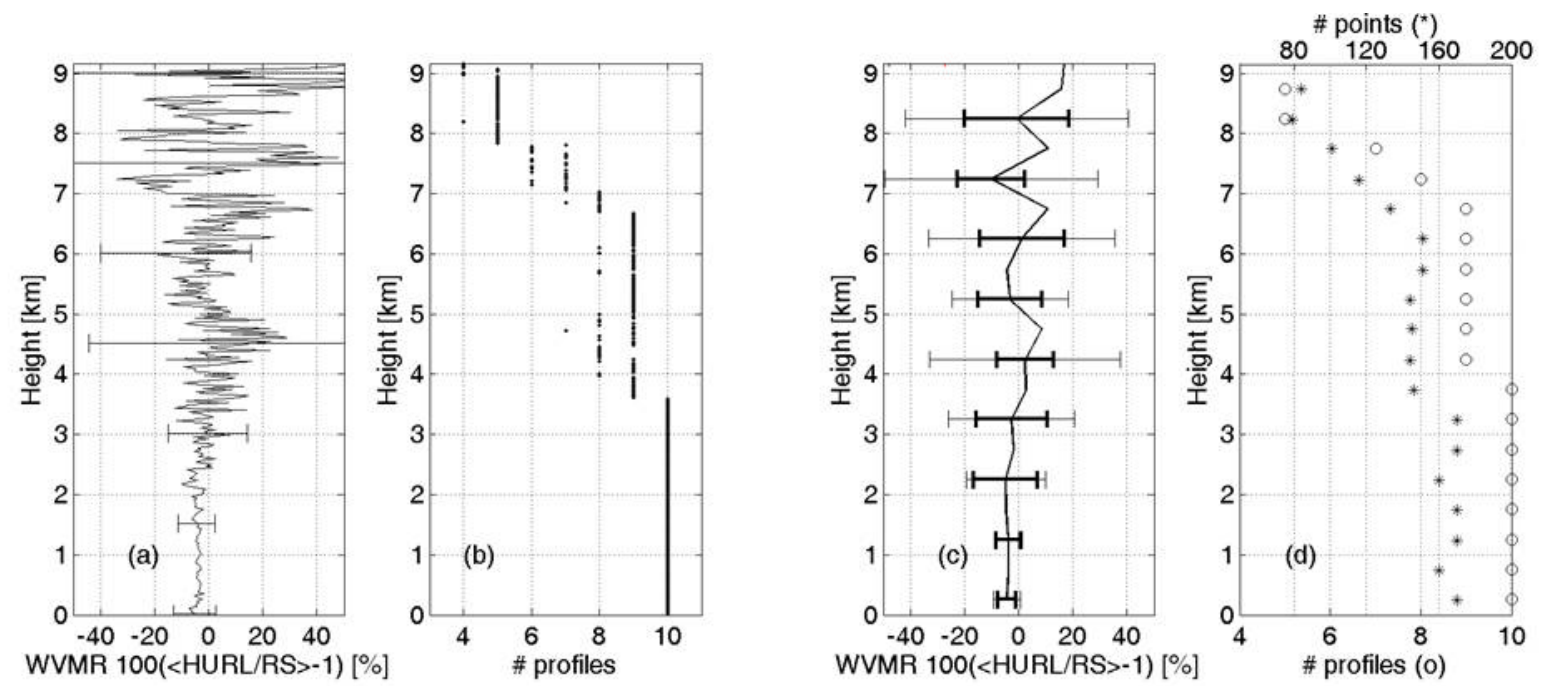

FIG. 4. Water vapor mixing ratio ensemble averaging for the night-time coincidences. (a) Relative difference with respect to RS92. The error bars represent the STD of over the number of profiles. (b) Number of profiles available for ensemble average. Altitude resolution for (a) and (b) is $30 \mathrm{~m}$. In (c), the thick error bars represent the STD over the number of profiles while the thin error bars represent the STD over all measurements (points) available in a block (See text for explanation). (d) Number of profiles (open circles) and number of points (asterisks) available for ensemble average for each $500 \mathrm{~m}$ block. 

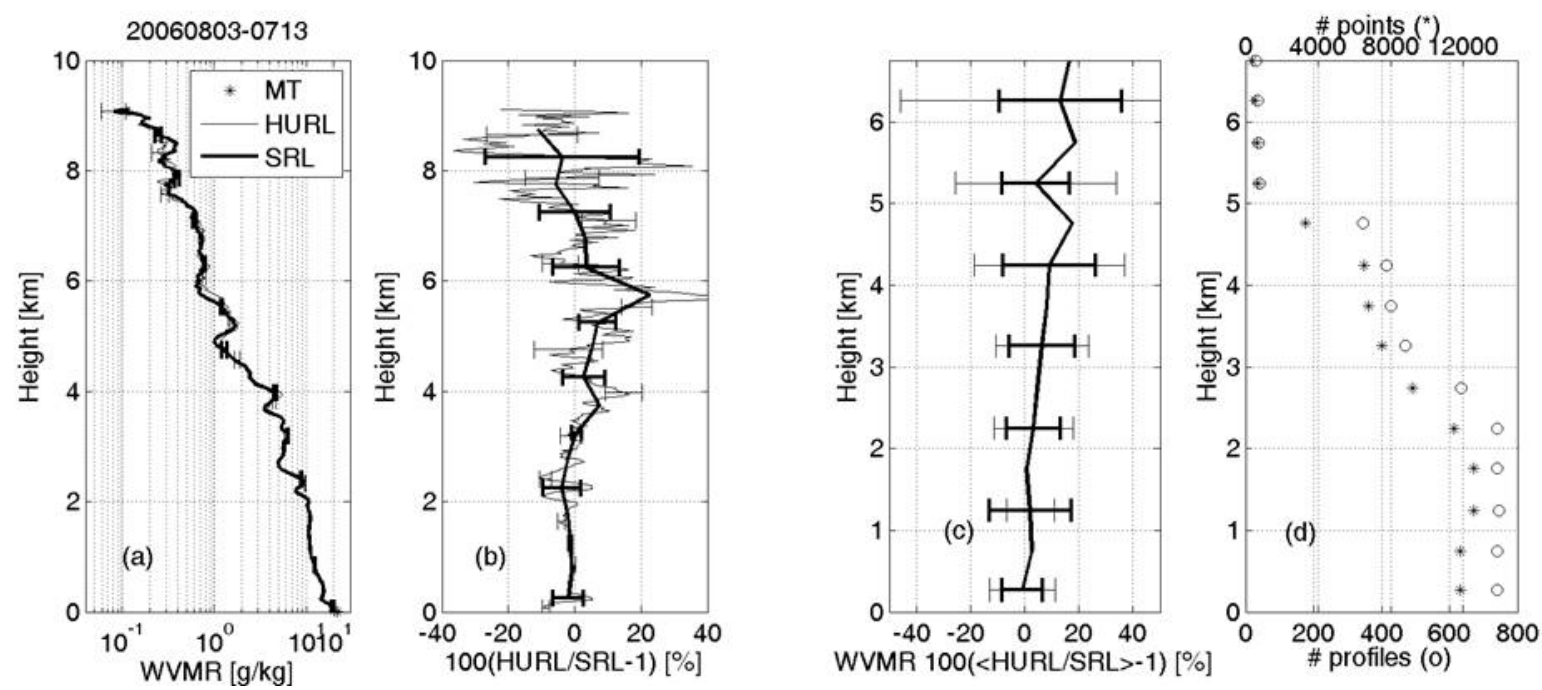

FIG. 5. (a) Water vapor mixing ratio as measured by HURL and SRL for 3 August 2006, 07:13 UT. MT stands for meteorological tower. (b) The relative difference between SRL and HURL. The thick curves and error bars represent the mean and STD over $500 \mathrm{~m}$ blocks. (c) Ensemble relative difference between HURL and SRL. The thin and thick errors bars are computed according to the two methods (see text). (d) Number of lidar profiles (open circles) and number of points (asterisks) available for each $500 \mathrm{~m}$ block. 

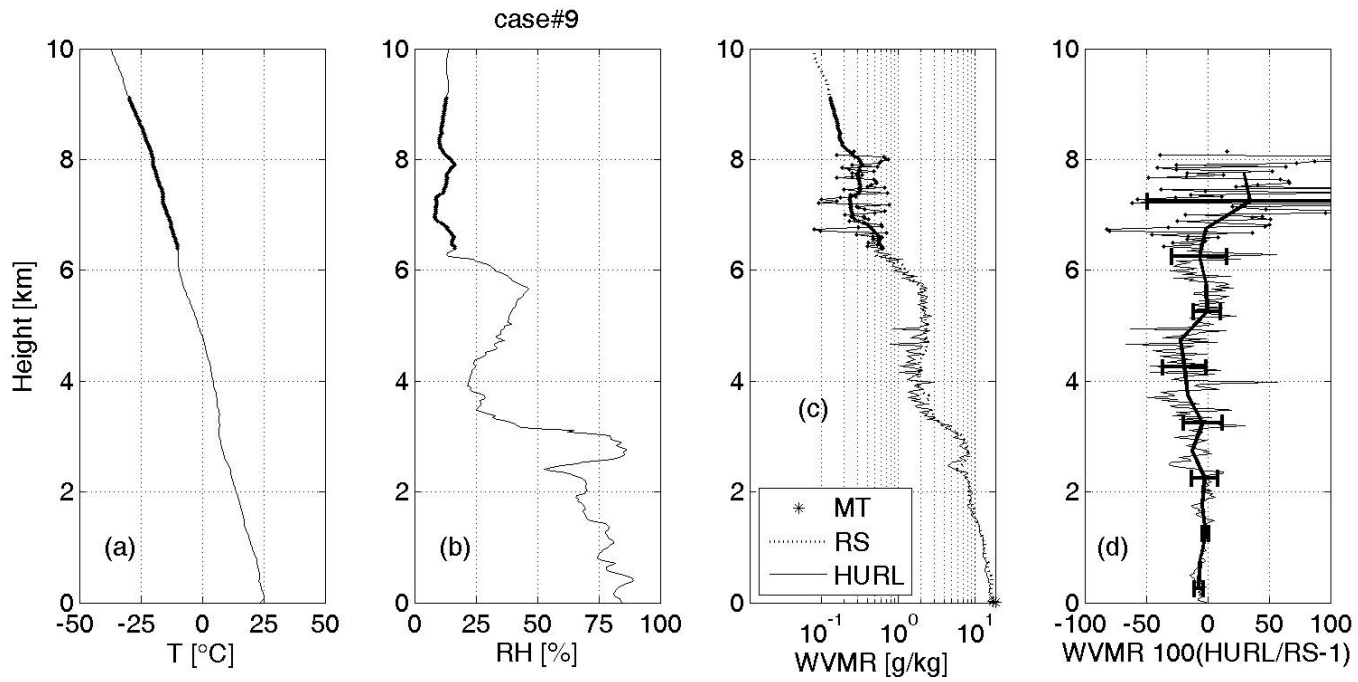

FIG. 6. Water vapor mixing ratio as measured by HURL and NWS Sippican Mark IIA on 27 July 2006, 3:36 UT. (a)-(b) Temperature and relative humidity during RS flight. (c) WVMR; MT stands for meteorological tower. (d) Relative difference with respect to RS. The Thick curve represents the mean profiles over $500 \mathrm{~m}$ blocks. 

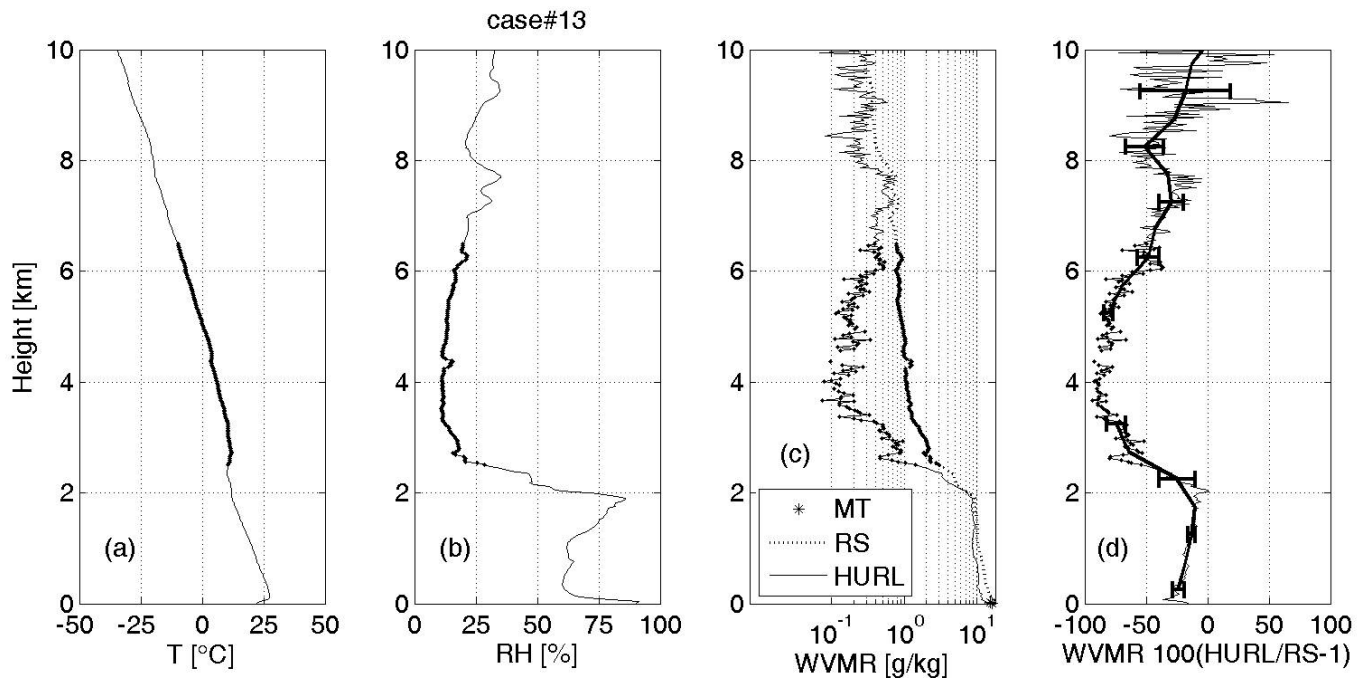

FIG. 7. Same as FIG. 6, for 5 August 2006, 3:30 UT. 

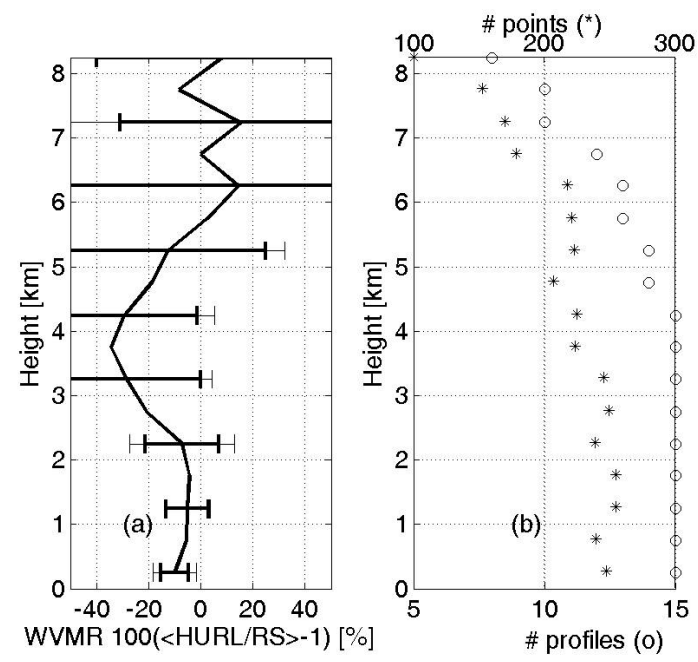

FIG. 8. (a) Relative difference with respect to Mark IIA. The thick error bars represent the STD over the number of profiles while the thin error bars represent the STD over all measurements (points) available in a block. See text for explanation. (b) Number of lidar profiles (open circles) and number of points (asterisks) available for each $500 \mathrm{~m}$ block. 

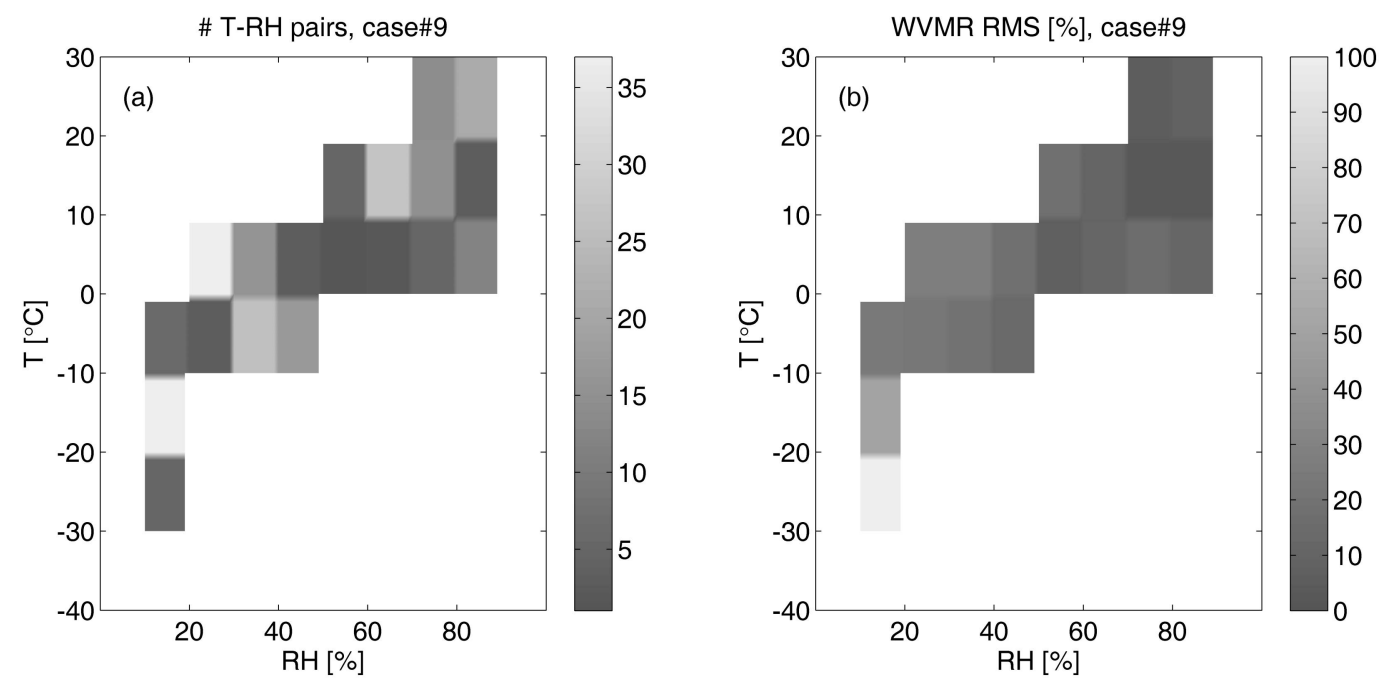

FIG. 9. HURL - Mark IIA RS grid comparison for 27 July 2006, 3:36 UT. (a) Number of events for each grid-box, characterized by $\Delta \mathrm{T}=10{ }^{\circ} \mathrm{C}$ and $\Delta \mathrm{RH}=10 \%$. (b) $R M S[\%]$ for each gridbox. The largest $R M S$ occurs over the region characterized by $\mathrm{T}=[-30,-20]{ }^{\circ} \mathrm{C}$ and $\mathrm{RH}=[10$, 20] $\%$. 

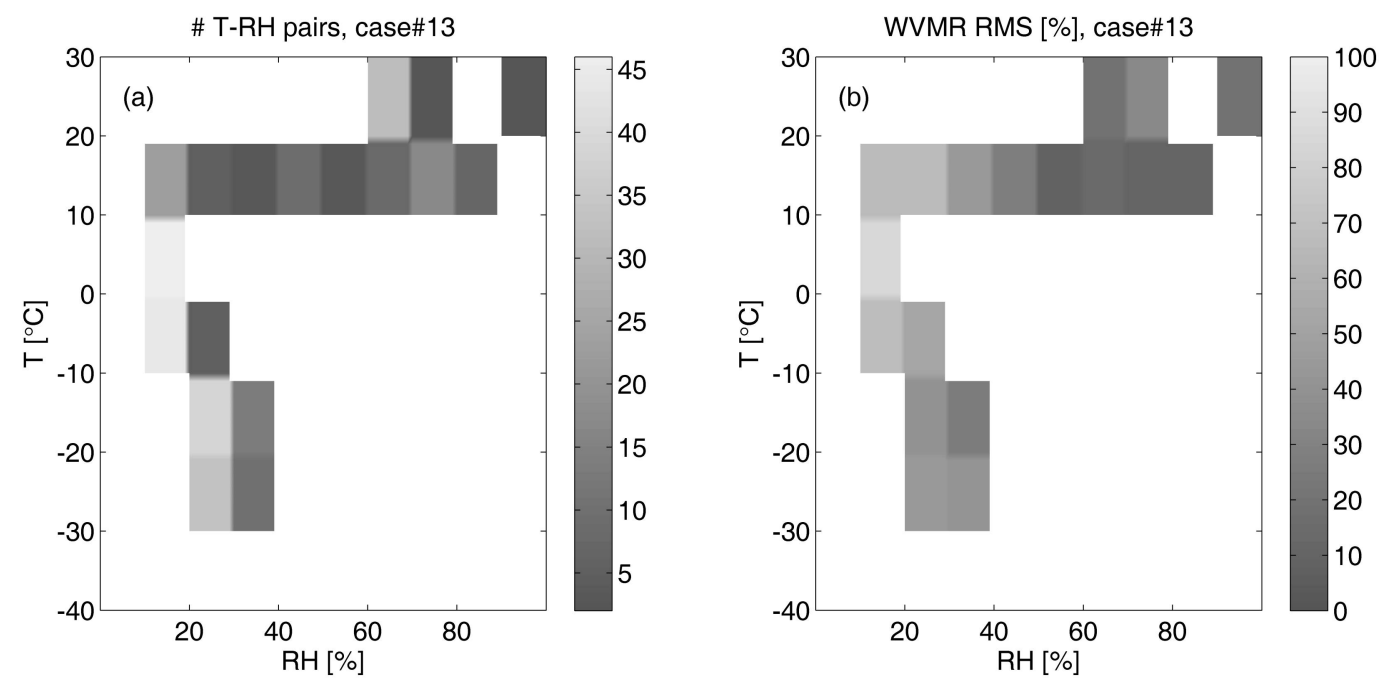

FIG. 10. HURL - Mark IIA RS grid comparison for 5 August 2006, 3:30 UT. (a) Number of events for each grid-box, characterized by $\Delta \mathrm{T}=10{ }^{\circ} \mathrm{C}$ and $\Delta \mathrm{RH}=10 \%$. (b) $R M S[\%$ ] for each box. The largest $R M S$ occurs over the region characterized by $\mathrm{T}=[0,10]{ }^{\circ} \mathrm{C}$ and $\mathrm{RH}=[10,20]$ $\%$. 

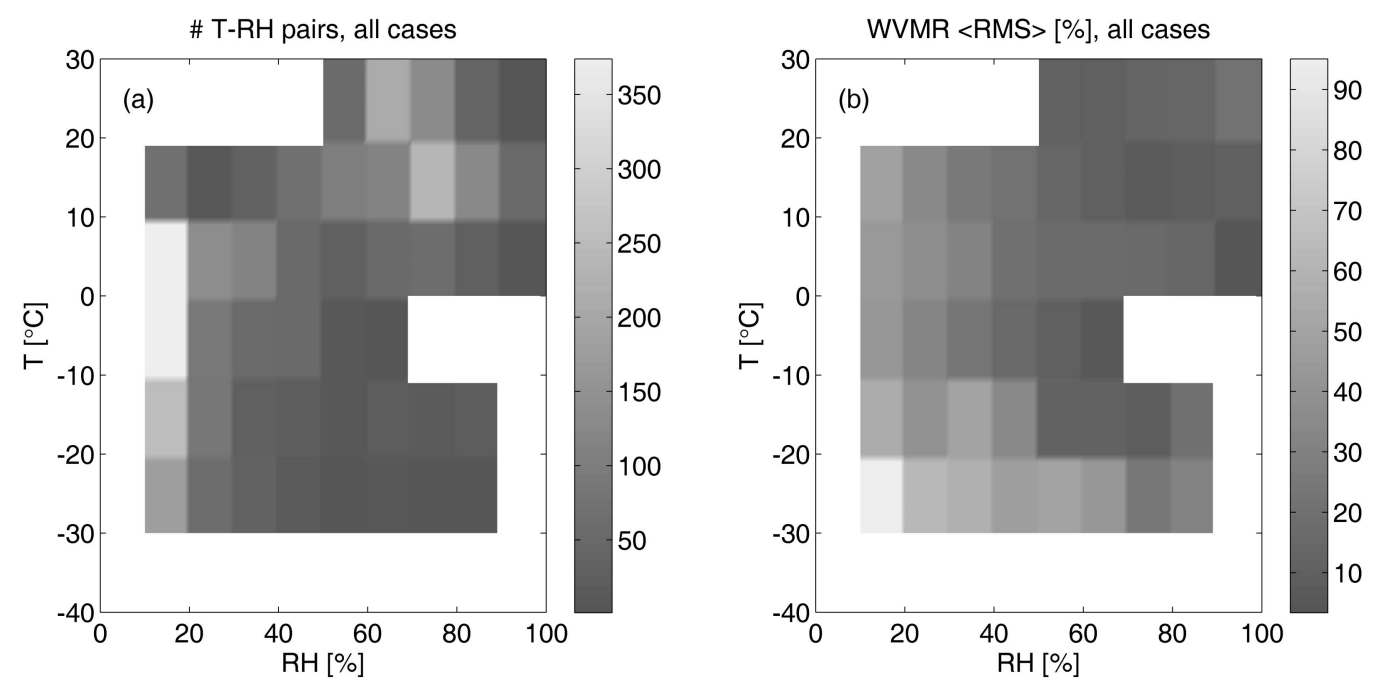

FIG. 11. HURL - Mark IIA RS grid comparison for the ensemble averaging over all 15 comparisons. (a) Number of events for each grid-box, characterized by $\Delta \mathrm{T}=10{ }^{\circ} \mathrm{C}$ and $\Delta \mathrm{RH}=$ $10 \%$. (b) $R M S[\%]$ for each grid-box. The largest $R M S$ occurs over the region with $\mathrm{T}=[-30,-20]$ ${ }^{\circ} \mathrm{C}$ and $\mathrm{RH}=[10,20] \%(\mathrm{RMS}=95 \%)$. Relatively large $R M S$ can be observed over regions with $\mathrm{T}=[-30,-20]{ }^{\circ} \mathrm{C}$ and $\mathrm{RH}=[20,30] \%(R M S=62.4 \%)$ and other regions with $\mathrm{T}=[-30,-20]{ }^{\circ} \mathrm{C}$ and $\mathrm{RH}=[20,70] \%$ or $\mathrm{T}=[-20,20]^{\circ} \mathrm{C}$ and $\mathrm{RH}=[10,20] \%$. 

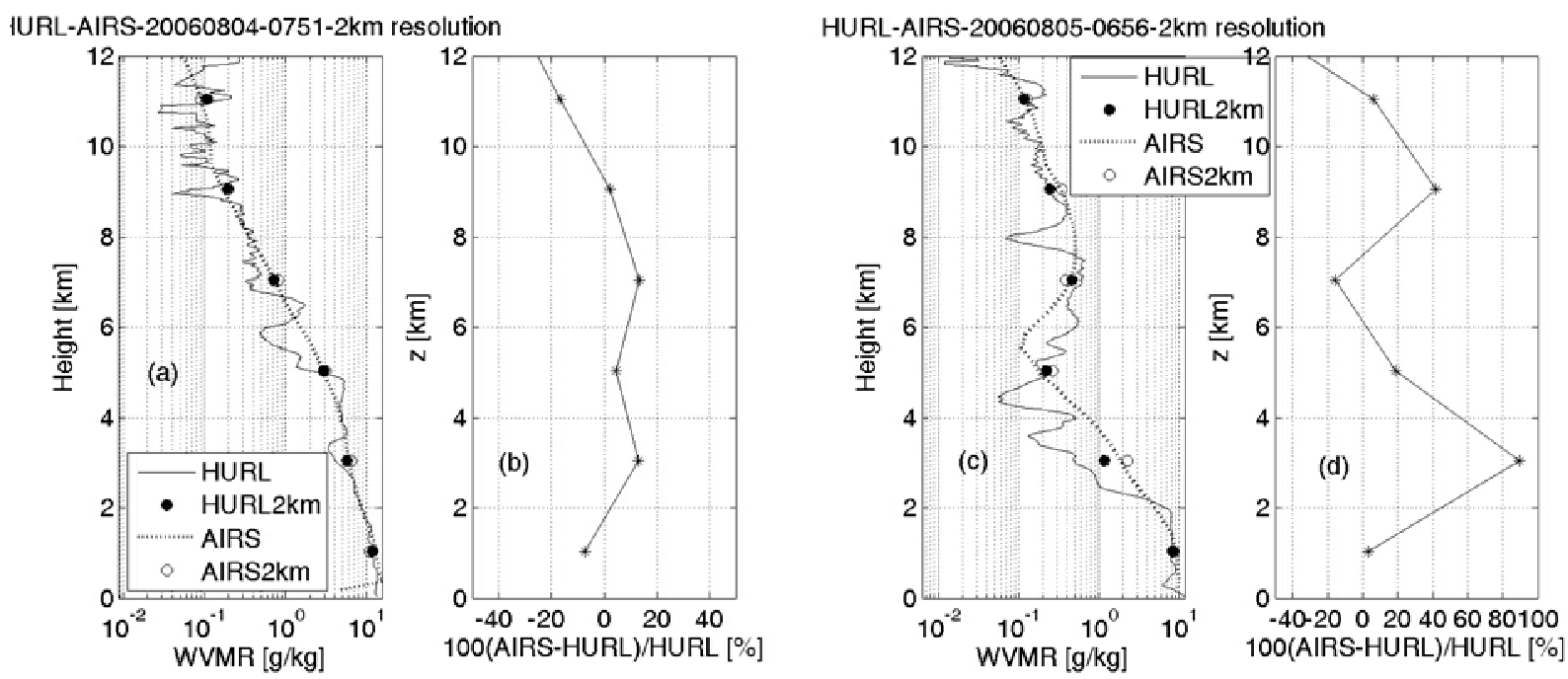

- (c) HURL-AIRS water vapor mixing ratio for 4 August 2006 (Aqua overpass 07:51 UT) and 5 August 2006 (Aqua overpass 06:56 UT). The HURL profiles are shown at both original resolution and averaged over $2 \mathrm{~km}$ layers. (b) - (d) Relative difference with respect to HURL within $2 \mathrm{~km}$ layers. 

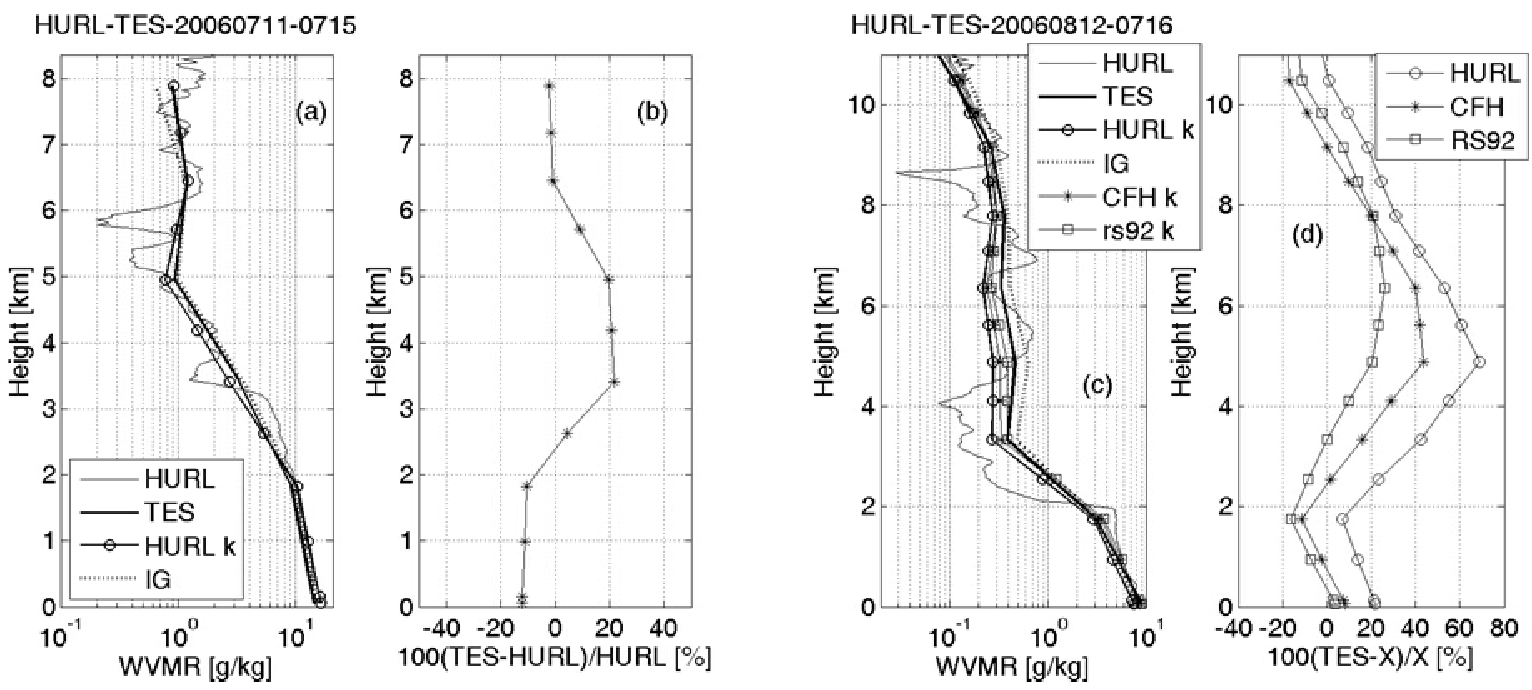

FIG. 13. (a) HURL-TES water vapor mixing ratio for 11 July 2006, Aura overpass 07:15 UT. (b) Relative difference with respect to HURL after applying a priori profile and kernels. (c) HURLTES-CFH-RS92 water vapor mixing ratio for 12 August 2006, Aura overpass 07:16 UT. (d) Relative difference with respect to HURL, CFH and RS92 after applying a priori profile and kernels. X stands for HURL, CFH or RS92. 